\title{
Transformation of Non-edible Vegetable Oils into Biodiesel Fuels Catalyzed by
}

\section{Unconventional Sulfonic acid-functionalized SBA-15}

\author{
Shih-Yuan Chen, ${ }^{\mathrm{a}}$ ( Supranee Lao-ubol, ${ }^{\mathrm{b}}$ Takehisa Mochizuki, ${ }^{\mathrm{a}}$ Yohko Abe, ${ }^{\mathrm{a}}$ Makoto \\ Toba, ${ }^{a}$ Yuji Yoshimura ${ }^{\mathrm{a}}$
}

\footnotetext{
${ }^{a}$ Resource Conversion Catalyst Group, Energy Technology Research Institute, National Institute of Advanced Industrial Science and Technology (AIST), 1-1-1 Higashi, Tsukuba, Ibaraki 305-8565, Japan.

${ }^{\mathrm{b}}$ Material Innovation Department, Thailand Institute of Scientific and Technological Research (TISTR), 35 Mu 3, Khlong 5, Khlong Luang, Pathum Thani 12120, Thailand.
}

To whom correspondence should be addressed:

Shih-Yuan Chen, Ph.D.

Researcher,

Resource Conversion Catalyst Group, Energy Technology Research Institute, National Institute of Advanced Industrial Science and Technology (AIST), 1-1-1 Higashi, Tsukuba, Ibaraki 305-8565, Japan.

TEL: +81-29-861-2680

FAX: +81-29-861-4532

E-mail: sy-chen@aist.go.jp 


\begin{abstract}
A real understanding of intrinsic acidity and catalytic property of unconventional and sulfonic acid-functionalized SBA-15 platelet catalysts synthesized with the aid of highly solvated $\mathrm{Zr}^{4+}$ salts (shortly termed SA-SBA-15-p) for transesterification of non-edible vegetable oils into biodiesel fuel (BDF) was reported, in comparison with conventional SBA-15 catalyst (shortly termed SBA-15-conv), unconventional SBA-15 platelet catalyst (shortly termed SBA-15-p) and commercial sulfonic resins of Amberlyst-15 and SAC-13. Thorough characterizations and catalytic study revealed that the content of fatty acid methyl ester (FAME) as the main component of BDF was increased in the order of SBA-15-conv $<$ SAC-13 $<$ SBA-15-p $<$ Amberlyst-15 < 5-25SA-SBA-15-p, which correlated closely with the loading, distribution, strength of acidic sites. Among them, the unconventional 15SA-SBA-15-p catalyst with proper loadings of propylsulfonic groups $\left(1.15 \mathrm{mmol} \mathrm{S}^{-1} \mathrm{~g}^{-1}\right)$ and superficial $\mathrm{Zr}^{4+}$ clusters (0.66 mmol g${ }^{-1}$ ) as a mixed solid Bronsted and Lewis acid, which had differential heat of $\mathrm{NH}_{3}$ adsorption in the range of 90-125 $\mathrm{kJ} \mathrm{mol}^{-1}$, gave highest FAME content with low concentrations of byproducts, such as glycerides and free fatty acid (FFA). In addition to high water and FFA tolerance levels, the used 15SA-SBA-15-p catalyst could be easily regenerated by ethanol extraction and its high activity was maintain. By contrast,
\end{abstract}


the SBA-15-conv catalyst without any Lewis and Bronsted acids had almost no activity in BDF synthesis. The unconventional SBA-15-p catalyst with superficial $\mathrm{Zr}^{4+}$ clusters as a pure solid Lewis acid gave a moderate FAME content accompanying with a high concentration of unreactive glycerides. Commercial sulfonic resins of Amberlyst-15 and SAC-13 with strongly phenylsulfonic and Nafion sulfonic groups as pure solid Bronsted acids gave moderate FAME contents accompanying with high concentrations of unreactive glycerides and unwanted FFA byproducts. Furthermore, they were significantly deactivated by water, FFA and regeneration treatment due to the poison and leaching of sulfonic groups and the decomposition of thermally unstable framework.

Keywords: mesoporous silica materials, solid Lewis and Bronsted acids, crude and non-edible vegetable oils, the water and FFA tolerance levels, reusability. 


\section{Introduction}

The demand of BDF as a renewable transportation fuel is rapid growth in the past decade in order to reduce our dependence on fossil fuel as a main source of transportation fuel according to the Kyoto protocol on emission control of greenhouse gases [1,2]. The Royal Thai Government has legislated that the blending ratio of petrol-diesel fuel and BDF must achieve 10\% in 2021, which is so-called "the renewable and alternative energy development plan for 25 percent in 10 years (AEDP: 2012-2021)” [3]. It is estimated that the BDF market in Thailand will be markedly enlarged to $5.97 \times 10^{6} \mathrm{~L}$ per day in 2021. However, BDF is currently synthesized through transesterfication of vegetable oils with methanol catalyzed by homogeneous alkali catalysts, such as $\mathrm{NaOH}$ or $\mathrm{NaOCH}_{3}$, under mild temperatures $\left(60-80{ }^{\circ} \mathrm{C}\right.$ ) and atmospheric pressure as well as heterogeneous base catalysts, such as a mixed oxide of zinc and aluminum in the Esterfif- $\mathrm{H}^{\mathrm{TM}}$ process, under extremely high temperatures $\left(210-260{ }^{\circ} \mathrm{C}\right)$ and pressures (10-70 Bar) [1,2,4-7]. Because FFA is highly reactive with alkali base catalyst to form the unwanted soap, which makes the separation and purification a difficult task, high-quality and edible vegetable oils with low FFA content $(<0.5 \mathrm{wt} \%)$ can be only used as oil feedstocks $[1,6,7]$. It has been discussed that BDF 
derived from high-quality and edible vegetable oils is costly and competing with food supply. When low-quality and non-edible vegetable oils are used as oil feedstocks, the pre-esterification unit catalyzed by sulfuric acid or para-toluenesulfonic acid is essential for removal of FFA prior to the main transesterification unit [1,8]. In addition to large amounts of waste water and spent catalysts, the anti-corrosive facilitates equipped with multiple separation and purification systems are needed for this integral process, causing high production cost. As a result, BDF seems to be neither environmental-friendly nor price compatible with petro-diesel. It is emergent to develop the innovative process, which is able to transform low-quality and non-edible vegetable oils into BDF through an environmental-friendly and cost-effective way.

Low-quality and non-edible vegetable oils with high FFA contents can be transformed into BDF by simultaneous esterification and transesterification catalyzed by solid acids [9-29]. Solid acids are generally classified into three groups: (i) commercial sulfonic resins, carbon and silica [11-14], such as Amberlyst-15, Nafion NR50 and SAC-13, (ii) inorganic materials [15-22], such as heteropolyacids, modified zirconium oxides, metal-incorporated porous silica and zeolite, and (iii) organic-inorganic hybrid materials [23-35], such as sulfonic acid-functionalized porous silica or clay. Among them, commercial sulfonic resins and conventional sulfonic 
acid-functionalized porous silica have been widely studied because of their relatively high activity in BDF synthesis. Kotadia and Soni recently reported that sulfonic acid-functionalized silica with ionic liquid moiety was an efficient solid acid catalyst for transesterication [35]. However, the deactivation of commercial and conventional sulfonic acid-based solid acids arisen from leaching of active site, formation of coke and decomposition of framework was frequently reported [26-31]. For examples, commercial sulfonic acid-functionalized amorphous silica was seriously deactivated after the first run of transesterification due to leaching of sulfonic groups and formation of organic deposits [30]. The activity of perfluorosulfonic acid-functionalized SBA-15 in synthesis of soybean-derived BDF was completely lost after the first regeneration due to that the perfluorosulfonic groups were totally leached into the reaction medium [31]. The recently studies had demonstrated that the unconventional SA-SBA-15-p catalyst synthesized with the aid of highly solvated $\mathrm{Zr}^{4+}$ salts was applicable as a new solid acid to the pre-esterification and transesterification processes [29,32]. However, the intrinsically acidic sites of the unconventional SA-SBA-15-p catalysts and their catalytic activities in BDF synthesis are still unclear. Herein, thorough characterizations and catalytic study with a variety of advanced techniques gave us new insights into the intrinsically acidic sites of the unconventional SA-SBA-15-p catalysts and their 
catalytic activities in transformation of non-edible vegetable oils into BDF. The results were compared with those of the SBA-15-conv catalyst without any Lewis and Bronsted acids, the unconventional SBA-15-p catalyst with superficial $\mathrm{Zr}^{4+}$ clusters as a solid Lewis acid, and commercial sulfonic resins of Amberlyst-15 and SAC-13 with phenylsulfonic or Nafion sulfonic groups as solid Bronsted acids. Particular concerns for the composition of BDF, the resistance to water and FFA, and the reusability of these sulfonic acid-containing catalysts were explored in detail.

\section{Experimental}

\subsection{Synthesis of the unconventional 5-25SA-SBA-15-p catalysts}

The unconventional 5-25SA-SBA-15-p catalysts were synthesized by the modified procedures of Chen et al. [32]. Typically, $4.0 \mathrm{~g}$ of P123 ( $\mathrm{M}_{\mathrm{n}}=5800$, Aldrich), $0.64 \mathrm{~g}$ of zirconium oxychloride octahydrate $\left(\mathrm{ZrOCl}_{2} \cdot 8 \mathrm{H}_{2} \mathrm{O}\right.$, Nakarai Chemicals), and $1.18 \mathrm{~g}$ of $\mathrm{NaCl}$ (Wako) were thoroughly dissolved in $160 \mathrm{~g}$ of $2 \mathrm{M} \mathrm{HCl}$ aqueous solution at $35^{\circ} \mathrm{C}$ under stirring. To this solution, $8.4 \mathrm{~g}$ of tetraethyl orthosilicate (TEOS, Strem Chemicals) was pre-hydrolyzed for $2 \mathrm{~h}$ before the addition of various amounts of 
3-mercaptotrimethoxysilane (MPTMS, Acros) as sulfur-containing silane and $3.6 \mathrm{~g}$ of $\mathrm{H}_{2} \mathrm{O}_{2}$ (Wako) as oxidizing agent. The gel compositions were 0.017 P123: 1 TEOS: 0.05-0.25 MPTMS: $0.05 \mathrm{ZrOCl}_{2} \cdot 8 \mathrm{H}_{2} \mathrm{O}: 1 \mathrm{NaCl}$ : $7.9 \mathrm{HCl}: 9 \mathrm{H}_{2} \mathrm{O}_{2}: 221 \mathrm{H}_{2} \mathrm{O}$. The synthesis gels sealed in polypropylene bottles were stirred at $35{ }^{\circ} \mathrm{C}$ for $22 \mathrm{~h}$, followed by hydrothermal treatment at $100{ }^{\circ} \mathrm{C}$ for $24 \mathrm{~h}$ under static condition. The as-made samples were obtained by filtering, washing with a large amount of water, and drying at $50{ }^{\circ} \mathrm{C}$ overnight. P123 was removed from the as-made samples by ethanol extraction at $78{ }^{\circ} \mathrm{C}$ for $24 \mathrm{~h}$. The resulting samples were designated as xSA-SBA-15-p, where $\mathrm{x}$ represented as the MPTMS/TEOS molar percentages in the gels.

\subsection{Reference catalysts}

The siliceous SBA-15-conv catalyst without any Lewis and Bronsted acids was synthesized by the procedures of Zhao et al. [36]. Typically, the SBA-15-conv catalyst was self-assembled in $160 \mathrm{~g}$ of $2 \mathrm{M} \mathrm{HCl}$ synthesis solution containing $4.0 \mathrm{~g}$ of P123 and $8.4 \mathrm{~g}$ of TEOS at $35{ }^{\circ} \mathrm{C}$ for $24 \mathrm{~h}$ under stirring, followed by hydrothermally treating at $100{ }^{\circ} \mathrm{C}$ for another $100{ }^{\circ} \mathrm{C}$ under a static condition. The gel composition was 0.017 P123: 1 TEOS: $7.9 \mathrm{HCl}: 221 \mathrm{H}_{2} \mathrm{O}$. The as-made sample was obtained by filtering, 
washing with $500 \mathrm{~mL}$ of deionized water and drying at $50{ }^{\circ} \mathrm{C}$ overnight. P123 was removed from the as-made sample by calcination at $500{ }^{\circ} \mathrm{C}$ for $12 \mathrm{~h}$ in air. As a result, the SBA-15-conv catalyst was obtained.

The preparation of the unconventional SBA-15-p catalyst was similar to that of SBA-15-conv catalyst, except the addition of highly solvated $\mathrm{Zr}^{4+}$ salts [33]. The gel composition was 0.017 P123: 1 TEOS: $0.05 \mathrm{ZrOCl}_{2} \cdot 8 \mathrm{H}_{2} \mathrm{O}$ : $7.9 \mathrm{HCl}: 221 \mathrm{H}_{2} \mathrm{O}$.

Commercial sulfonic resins of Amberlyst-15 (Alfa Aesor) and SAC-13 (Sigma-Aldrich) were used as received. SAC-13 with highly thermal stability up to 200 ${ }^{\circ} \mathrm{C}$ is made of nanoporous silica matrix embedded with Nafion sulfonic resin (10-20 wt\%). Amberlyst-15 with moderately thermal stability up to $120{ }^{\circ} \mathrm{C}$ is made of macroreticular polystyrene functionalized with phenyl sulfonic acids.

\subsection{Characterizations}

The pore structures were evaluated by powder X-ray diffraction pattern (XRD) using a Bruker AXS D8 advance diffractrometer with $\mathrm{Cu} \mathrm{K} \alpha$ radiation $(\lambda=1.54 \AA$ ) as X-ray light source. The operation voltage and current were set at $40 \mathrm{kV}$ and $40 \mathrm{~mA}$, respectively. The small-angle XRD patterns were collected in the $2 \theta$ range of $0.5-5^{\circ}$ 
using a $\mathrm{NaI}(\mathrm{T} 1)$ scintillation type detector. The $\mathrm{N}_{2}$ adsorption-desorption isotherms were measured by a BELSORP 28SA instrument at $77 \mathrm{~K}$. Prior to analysis, the samples (around $0.10 \mathrm{~g}$ ) were degassed at $120{ }^{\circ} \mathrm{C}$ under high vacuum $(<50 \mathrm{~Pa})$. The specific surface area $\left(\mathrm{S}_{\mathrm{BET}}\right)$ was calculated by Brunauer-Emmett-Teller (BET) method in the $P / P_{0}$ region of $0.05-0.25$. The total pore volume $\left(\mathrm{V}_{\text {total }}\right)$ was accumulated up to $P / P_{0}$ of 0.95. The pore diameter $\left(\Phi_{\mathrm{p}}\right)$ was obtained from the peak maximum of adsorption pore size distribution (PSD), calculated by a modified Broekhoff-de Boer method with the Frenkel-Halsey-Hill equation (BdB-FHH) [37,38]. The thermogravimetric analysis (TGA) and differential thermal analysis (DTA) were measured by a Rigaku ThermoPlusEvo2 TG8120 instrument. The samples (around $10 \mathrm{mg}$ ) placed in an alumina holder were heated to $800{ }^{\circ} \mathrm{C}$ with a ramping rate of $10{ }^{\circ} \mathrm{C} \min ^{-1}$ under an air flow of $100 \mathrm{~mL} \mathrm{~min}{ }^{-1}$. Diffuse-reflectance infrared Fourier transform (DRIFT) spectra of pyridine adsorption were recorded by a Thermo Nicolet Nexus 870 FT-IR instrument equipped with a small collector of in situ DRIFT cell at $100-300{ }^{\circ} \mathrm{C}$ in He flow. Before acquired DRIFT spectra, the samples (10 mg) mixed with $\mathrm{KBr}(90 \mathrm{mg})$ were pre-treated at $120-300{ }^{\circ} \mathrm{C}$ for $30 \mathrm{~min}$ in He flow in order to remove the physically adsorbed $\mathrm{H}_{2} \mathrm{O}$ and $\mathrm{CO}_{2}$ molecules. Note that the Amberlyst-15 and SAC-13 catalysts were pre-treated at 120 and $200{ }^{\circ} \mathrm{C}$, respectively. The differential heats of $\mathrm{NH}_{3}$ adsorption were measured 
by a CSA-450G micro-calorimeter (Tokyo Riko, Co. Ltd., Tokyo) at $50{ }^{\circ} \mathrm{C}$. Prior to the analysis, the samples (0.60-1.2 g) were degassed at $120-200{ }^{\circ} \mathrm{C}$ for $1 \mathrm{~h}$ under high vacuum $(<10 \mathrm{~Pa})$. The high-resolution scanning electron microscope (HRSEM) photos were taken by a JEOL JFC-1100 field emission SEM instrument. Before the measurement, the samples were coated by a thin layer of gold. The sulfur contents in BDFs and in solids were analyzed by a TS-100V trace sulfur analyzer and Leco Truespec sulfur analyzer, respectively. Diffuse-reflectance (DR) UV-Vis spectra were recorded by a JASCO V-570 spectrometer with an integrating sphere detector, where barium sulfate was used as a reference material.

\subsection{Synthesis and analysis of BDF}

Transformation of crude Jatropha oil (CJO) as non-edible vegetable oil into BDF, a mixture consisted mainly of FAMEs with different lengths of carbon chains, was performed on a high-pressure batch-type stainless steel reactor (internal diameter $=1.8$ $\mathrm{cm}$, internal height $=30 \mathrm{~cm}$, volume $=76.3 \mathrm{~mL}$ ) lined with a glass tube (internal diameter $=1.5 \mathrm{~cm}$, internal height $=28.2 \mathrm{~cm}$ and volume $=46.4 \mathrm{~mL}$ ) at $200{ }^{\circ} \mathrm{C}$ in $\mathrm{N}_{2}$ atmosphere. The molecular weight, acid value and FFA profile of various vegetable oils 
were analyzed by a modified IUPAC method (Table S1, ESI) [21,22]. In the typical reaction, $2.5 \mathrm{~g}$ of CJO, $2.5 \mathrm{~g}$ of methanol and $0.375 \mathrm{~g}$ of dried catalyst were sealed in the glass-lined stainless steel reactor and purged with $\mathrm{N}_{2}$ for five times. The methanol-to-CJO molar ratio and the catalyst-to-CJO weight percentage were 27 and 15, respectively. To start the reaction, the stainless steel reactor was quickly inserted into a pre-heated electric furnace with a vibration frequency of $0.5 \mathrm{~s}^{-1}$. After the specific reaction period, the stainless steel reactor was removed from the electric furnace and quickly air-cooled to the ambient temperature. The solid catalyst was removed from the reaction mixture through the syringe filter. The resulting reaction mixture was dried by the rotary evaporator at $80{ }^{\circ} \mathrm{C}$. The BDF part was then collected by discarding the lower layer of glycerol and qualitatively analyzed by an Agilent 6890N GC-MS instrument equipped with a HP-1 column. The used catalysts were regenerated by ethanol extraction at $78{ }^{\circ} \mathrm{C}$ for 1 day, followed by washing with methanol for several times and drying at $50{ }^{\circ} \mathrm{C}$ overnight.

The weight percentages of free glycerol $(G)$ and residual monoglycerides (MG), diglycerides (DG) and triglycerides (TG) in the BDF samples were quantitatively determined by the procedures of EN14105 method using an Agilent 6890N GC-FID instrument equipped with a DB-5HT column [22]. Typically, the BDF samples (around 
0.10 g) were silylated by N-methyl-N-trimethylsilyltrifluoroacetamide (MSTFA, TCI), followed by mixing with 1,2,4-butanetriol (TCI) as an internal standard intended for the determination of the $\mathrm{G}$ content, and 1,2,3-tricaprolglycerol (Acros) as an internal standard intended for the determinations of the MG, DG and TG contents, and then diluted by heptane (Wako). The total glycerol $\left(\mathrm{G}_{\mathrm{T}}\right)$ content in weight percentage was calculated by the equation 1 .

$\mathrm{G}_{\mathrm{T}}=\mathrm{G}+0.255 \mathrm{MG}+0.146 \mathrm{DG}+0.103 \mathrm{TG}$

The weight percentages of FAME and FFA in the BDF samples were quantitatively determined by the modified procedures of EN14103 using an Agilent 6890N GC-FID instrument equipped with a HP-1 column [22]. Typically, the BDF samples (around 0.10 g) were silylated by MSTFA, followed by mixing with methyl heptadecanoate (Acros) as an internal standard intended for the determinations of FAME and FFA, and then diluted by heptane. The FAME or FFA content in weight percentage is calculated by the equation 2.

$\mathrm{C}=\frac{\sum A}{A_{M P}} \times \frac{C_{M P} \times V_{M P}}{m} \times 100 \%$ 
Where, $\mathrm{C}$ is the weight percentage of FAME or FFA, $\Sigma \mathrm{A}$ is the sum of peak areas of FAME in $\mathrm{C}_{12}$ to that in $\mathrm{C}_{24}, \mathrm{~A}_{\mathrm{MP}}$ is the peak area of methyl heptadecanote, $\mathrm{C}_{\mathrm{MP}}$ is the concentration, in $\mathrm{mg} / \mathrm{mL}$, of methyl heptadecanote being used, $\mathrm{V}_{\mathrm{MP}}$ is the volume, in $\mathrm{mL}$, of methyal heptadecanoate solution being used, and $\mathrm{m}$ is the weight, in mg, of the sample.

\section{Results and discussion}

\subsection{Structural and acidic characterizations}

The mesoporous structures of the unconventional 5-25SA-SBA-15-p catalysts were examined by small-angle XRD patterns and $\mathrm{N}_{2}$ adsorption-desorption isotherms, in comparison with the reference catalysts. Fig. 1(a) shows that the unconventional SBA-15-p and 5-15SA-SBA-15-p catalysts have three distinct diffraction peaks in the $2 \theta$ range of $0.5-2.0^{\circ}$, indexed as the (100), (110) and (200) planes of 2D hexagonal p6mm structure in a sequence from left to right. This result is consistent with those of the SBA-15-conv catalyst and the original paper reported by Zhao et al. [36]. Their 
corresponding $\mathrm{N}_{2}$ adsorption-desorption isotherms in Fig. 1(b) have a classical type IV isotherm with a steep $\mathrm{H}_{1}$ hysteresis loop appeared at a relatively large $P / P_{0}$ range of $0.60-0.85$, associated with the largely channeling pores. The pore diameters of the unconventional SBA-15-p and 5-25SA-SBA-15-p catalysts synthesized with the aid of highly solvated $\mathrm{Zr}^{4+}$ salts are slightly larger than that of the SBA-15-conv catalyst. When the MPTMS/TEOS molar ratio is equal to or higher than 0.20 , the unconventional 20-25SA-SBA-15-p catalysts have relatively weak diffraction peaks and broad hysteresis loops shifted toward relatively low $P / P_{0}$ region. It suggests that the channeling pores are partially blocked by such high loadings of propylsulfonic groups.

Commercial sulfonic resins of Amberlyst-15 and SAC-13 show a broad X-ray diffraction peak in the wide-angle region and a steep hysteresis loop in relatively high $P / P_{0}$ region of $0.8-0.95$. It is attributed to the amorphous and disordered porous frameworks (Fig. S1, ESI).

From the optic photos, the SBA-15-conv, unconventional SBA-15-p and unconventional 5-25SA-SBA-15-p catalysts are in the form of white powder whereas the extruded SAC-13 and Amberlyst-15 catalysts are in the forms of white rods and gray spheres, respectively (Fig. S2, ESI). From the HRSEM photos, the SBA-15-conv, unconventional SBA-15-p and unconventional 5-25SA-SBA-15-p catalysts are 
hexagonal platelets with 200-350 $\mathrm{nm}$ in thickness and 1-1.5 m in width (Figs. 2(a-b) and S3, ESI). Noteworthily, the lengths of the channeling pores are equal to the widths of the platelets. The shortly channeling pores have a great benefit to the molecular diffusion when the platelets are applied as catalysts or adsorbents [37,39]. On the other hand, the HRSEM photos show that the SAC-13 and Amberlyst-15 catalysts are large aggregates consisted of many irregular nanoparticles.

Table 1 compares the structural property and sulfur loading of the unconventional 5-25SA-SBA-15-p and reference catalysts. The SBA-15-conv catalyst has large $\mathrm{S}_{\mathrm{BET}}$, $\mathrm{V}_{\text {Total }}$ and $\Phi_{\mathrm{p}}$ values, similar to the literature reports $[33,36]$. The unconventional SBA-15-p catalyst with relatively large $\mathrm{V}_{\text {Total }}$ and $\Phi_{\mathrm{p}}$ values gives relatively low $\mathrm{S}_{\mathrm{BET}}$ value. For the unconventional 5-25SA-SBA-15-p catalysts, the $S_{\mathrm{BET}}, \mathrm{V}_{\text {total }}$ and $\Phi_{\mathrm{p}}$ values are gradually decreased as the MPTMS/TEOS molar ratios in the gels are increased whereas the sulfur loadings show an opposite trend. It suggests that the propylsulfonic groups are indeed incorporated in the unconventional 5-25SA-SBA-15-p catalysts prepared by one-pot co-condensation method.

The SAC-13 catalyst with lowest sulfur loading has moderate $\mathrm{S}_{\mathrm{BET}}$ and $\mathrm{V}_{\text {total }}$ values, associated with the porous silica framework. The Amberlyst-15 catalyst with largest sulfur loading has low $\mathrm{S}_{\mathrm{BET}}$ and $\mathrm{V}_{\mathrm{p}}$ values, due to the densely organic framework. The 
ultra-large $p$ values of SAC-13 and Amberlyst-15 catalysts are related to the aggregation voids of the irregular nanoparticles as observed in the HRSEM photos.

The organic loading and thermal stability of the unconventional 5-25SA-SBA-15-p and reference catalysts were determined by the TGA-DTA technique (Fig. 3). Since the catalytically active sites are related to the sulfonic groups, the unconventional 5-25SA-SBA-15-p catalysts after the removal of P123 were measured. For the as-made SBA-15-conv catalyst, the one-step weight loss with a DTA peak centered at $191{ }^{\circ} \mathrm{C}$ is observed. It is associated with the decomposition of P123 triblock copolymer embedded in the mesoporous silica framework [36]. For the as-made SBA-15-p catalyst, the one-step weight loss is increased to $43.9 \mathrm{wt} \%$ and its corresponding DTA peak is moved to $315{ }^{\circ} \mathrm{C}$. It is assigned as the decomposition of P123 triblock copolymer embedded in the mesoporous silica framework with superficial $\mathrm{Zr}^{4+}$ clusters [33]. The unconventional SBA-15-p catalyst is prepared by the fast self-assembly of P123 micelles and TEOS accelerated by the highly solvated $\mathrm{Zr}^{4+}$ ions. As a result, the $\mathrm{Zr}^{4+}$ species are naturally incorporated in the superficial area of the unconventional SBA-15-p catalyst and its loading is around $0.61 \mathrm{mmol} \mathrm{g}^{-1}$ (Table 1). For the unconventional 15SA-SBA-15-p catalyst, the weight loss associated with the decomposition of P123 triblock copolymer is diminished to $2.2 \mathrm{wt} \%$, indicating that P123 is nearly removed by ethanol extraction. 
A new weight loss (12.8 wt\%) is appeared in the temperature region of $350-580{ }^{\circ} \mathrm{C}$ and its corresponding DTA peak is centered at $450{ }^{\circ} \mathrm{C}$. This new weight loss is associated with the decomposition of propylsulfonic groups [40]. According to the TGA-DTG analysis, the amounts of propylsulfonic groups in the unconventional 5-25SA-SBA-15-p catalysts are around 8.2-14.3 wt\%, proportional to the MPTMS/TEOS molar ratios in the gels (Table S2 and Fig. S4, ESI). It is another indication that the propylsulfonic groups are indeed incorporated in the unconventional 5-25SA-SBA-15-p catalysts.

The TGA-DTA profile of the SAC-13 catalyst resembles that of the unconventional 15SA-SBA-15-p catalyst. A steep weight loss of $12.2 \mathrm{wt} \%$ is appeared in the temperature region of $380-500{ }^{\circ} \mathrm{C}$, associated with the decomposition of Nafion sulfonic groups. For the Amberlyst-15 catalyst, the weight loss can be divided into three parts. The weight loss in the temperature region of $50-150{ }^{\circ} \mathrm{C}$ is $18.6 \mathrm{wt} \%$, due to the removal of physically adsorbed water. Another weight loss in the temperature region of 150-400 ${ }^{\circ} \mathrm{C}$ is $27.8 \mathrm{wt} \%$, associated with the decomposition of polystyrene framework. The other weight loss in the temperature region of $400-600{ }^{\circ} \mathrm{C}$ is $51.1 \mathrm{wt} \%$, associated with the decomposition of phenylsulfonic groups [41].

The chemical environment of superficial $\mathrm{Zr}^{4+}$ clusters in the unconventional 
SBA-15-p and 5-25SA-SBA-15-p catalysts were examined by DR UV-Vis spectra, in comparison with those of SBA-15-conv, tetragonal $\mathrm{ZrO}_{2}$ and $\mathrm{ZrOCl}_{2} \cdot 8 \mathrm{H}_{2} \mathrm{O}$ (Fig. 4). $\mathrm{ZrOCl}_{2} \cdot 8 \mathrm{H}_{2} \mathrm{O}$ is a hydroxide-containing cluster in the form of $\left[\mathrm{Zr}_{4}(\mathrm{OH})_{8}\left(\mathrm{H}_{2} \mathrm{O}\right)_{16}\right]^{8+}$, where the 8-coordinated $\mathrm{Zr}^{4+}$ cation is located in distorted square antiprismatic structure $[42,43]$. An intense absorbance centered at $204 \mathrm{~nm}$ is due to the ligand to metal charge transfer (LMCT) transition from $\mathrm{O}^{2-}$ to 8-coordinated $\mathrm{Zr}^{4+}$. In tetragonal $\mathrm{ZrO}_{2}$, the 8-coordinated $\mathrm{Zr}^{4+}$ cation is surrounded by $\mathrm{O}^{2-}$ anions with two sets of $\mathrm{Zr}-\mathrm{O}$ bondings. A broad absorbance in the range of $200-270 \mathrm{~nm}$ is consisted of two bands centered at 217 $\mathrm{nm}$ and $230 \mathrm{~nm}$, corresponding to the LMCT and band gap transitions, respectively [43]. The SBA-15-conv catalyst without any $\mathrm{Zr}^{4+}$ species has no absorbance in the UV-Vis region. On the contrary, the unconventional SBA-15-p and 5-25SA-SBA-15-p catalysts show a distinct LMCT transition centered at 206-209 nm accompanying with a weak band gap transition on the right. Because the LMCT bands are weak and the band gaps are blue-shifted, the $\mathrm{Zr}^{4+}$ species in the unconventional SBA-15-p and 5-25SA-SBA-15-p catalyst are probably formed as zirconia clusters, similar to or smaller than the $\left[\mathrm{Zr}_{4}(\mathrm{OH})_{8}\left(\mathrm{H}_{2} \mathrm{O}\right)_{16}\right]^{8+}$ tetramer.

The intrinsically acidic nature of the unconventional 5-25SA-SBA-15-p and reference catalysts is carefully examined by means of the DRIFT spectra of pyridine 
adsorbed at $100{ }^{\circ} \mathrm{C}$ and then recorded at $100-300{ }^{\circ} \mathrm{C}$ in He. According to the literature reports [44-46], the C-C stretching of pyridine coordinately bonded to Lewis acid site is appeared at around $1447-1460 \mathrm{~cm}^{-1}$, the C-C stretching of pyridinium ion formed by proton transfer from Bronsted acid site is appeared at around 1540 and $1640 \mathrm{~cm}^{-1}$, and the pyridine molecule hydrogen-bonded to surface hydroxyl group is appeared at around 1440-1447 $\mathrm{cm}^{-1}$. Fig 5 shows the DRIFT spectrum of pyridine adsorbed on the unconventional 15SA-SBA-15-p catalyst recorded at $100{ }^{\circ} \mathrm{C}$. The moderate bands centered at 1540 and $1637 \mathrm{~cm}^{-1}$ are associated with the pyridinium ions on propylsulfonic groups as Bronsted acid sites (Scheme 1). The strong band centered at $1447 \mathrm{~cm}^{-1}$ should have to do with the coordinately bonded pyridine molecules on superficial $\mathrm{Zr}^{4+}$ clusters as Lewis acid sites and the hydrogen-bonded pyridine molecules on surface silanol groups as weakly acidic sites (Scheme 1). When the DRIFT spectra are recorded at $150-200{ }^{\circ} \mathrm{C}$, the $1540 \mathrm{~cm}^{-1}$ band is maintained whereas the $1447 \mathrm{~cm}^{-1}$ band is significantly weakened accompanying with disappearance of $1596 \mathrm{~cm}^{-1}$ band. Fig. 5(b) further shows that the broad band centered at ca. $3375 \mathrm{~cm}^{-1}$, associated with the stretching vibration of pyridine molecules, is significantly weakened whereas the sharp band centered at $3735 \mathrm{~cm}^{-1}$, associated with the stretching vibration surface silanol groups, is almost double. The results suggest that most of pyridine 
molecules hydrogen-bonded to surface silanol groups have been removed. Therefore, the $1447 \mathrm{~cm}^{-1}$ band is mostly derived from the pyridine molecules coordinately bonded on superficial $\mathrm{Zr}^{4+}$ clusters when the DRIFT spectra are recorded at $200{ }^{\circ} \mathrm{C}$ or higher temperature.

Fig. 6 compares the intrinsically acidic nature of the unconventional 5-25SA-SBA-15 and reference catalysts recorded at $200{ }^{\circ} \mathrm{C}$. No bands are observed in the region of $1400-1700 \mathrm{~nm}$, confirming that the SBA-15-conv catalyst has no Lewis and Bronsted acid sites. The unconventional SBA-15-p catalyst shows a sharp band centered at $1447 \mathrm{~cm}^{-1}$, associated with the pyridine molecules coordinately bonded on superficial $\mathrm{Zr}^{4+}$ clusters as Lewis acid sites. Commercial sulfonic resins of Amberlyst-15 and SAC-13 show a characteristic band centered at $1540 \mathrm{~cm}^{-1}$, which is related to the pyridinium ions on phenylsulfonic or Nafion sulfonic groups as Bronsted acid sites. The weak band centered at $1444-1445 \mathrm{~cm}^{-1}$ should have to do with the pyridine molecules adsorbed on the organic hydroxyl or carboxylic groups. For the unconventional 5-25SA-SBA-15-p catalysts, the $1540 \mathrm{~cm}^{-1}$ band is increased by increase of the sulfur loadings, associated with the pyridinium ions adsorbed on propylsulfonic groups as Bronsted acid sites. Whereas. the $1447 \mathrm{~cm}^{-1}$ band is nearly unchanged by varying the sulfur loadings, suggesting that the amounts of superficial 
$\mathrm{Zr}^{4+}$ clusters as Lewis acid sites in the unconventional 5-25SA-SBA-15 catalysts are almost the same. This result is consistent with the ICP-AES study (Table 1, column 5).

The acid strength and capacity of the unconventional 5-25SA-SBA-15-p and reference catalysts were precisely determined by the $\mathrm{NH}_{3}$ chemisorption technique equipped with a micro-calorimeter at $50{ }^{\circ} \mathrm{C}$ (Fig. 7). The acid capacity is equal to the maximum uptake of $\mathrm{NH}_{3}$ adsorbed on these catalysts. Table 1 shows that the acid capacity is increased in the order of SAC-13 $<$ SBA-15-conv $<$ SBA-15-p $<$ 5-25SA-SBA-15-p < Amberlyst-15. Note that that the acid capacity determined by the $\mathrm{NH}_{3}$ chemisorption technique is higher than that by the conventional acid-base titration method. It is the fact that the conventional acid-base titration method is unable to determine the Lewis acids and weakly acidic sites, such as surface carboxylic and hydroxyl groups (-COOH, Si-OH and Zr-OH).

On the basis of the differential heat of $\mathrm{NH}_{3}$ adsorption, the strengths of the acidic sites are classified as strongly acidic (> $110 \mathrm{~kJ} \mathrm{~mol}^{-1}$ ), moderately acidic (90-110 kJ $\left.\mathrm{mmol}^{-1}\right)$ and weakly acidic $\left(<90 \mathrm{~kJ} \mathrm{mmol}^{-1}\right)$ sites [47]. Table 1 shows that the Amberlyst-15 catalyst has large amounts of strongly and moderately acidic sites (4.46 mmol $\left.\mathrm{H}^{+} \mathrm{g}^{-1}\right)$ and a small amount of weakly acidic site $\left(0.410 \mathrm{mmol} \mathrm{\textrm {H } ^ { + }} \mathrm{g}^{-1}\right)$. The amounts of strongly and moderately acidic sites are very close to the sulfur loading 
analyzed by the elemental analysis and the acid capacity determined by the conventional acid-base method. It can be said that the strongly and moderately acidic sites are mostly associated with the phenylsulfonic groups [48]. The weakly acidic site should have to do with the surface carboxylic or hydroxyl groups $[44,46]$. The SAC-13 catalyst has small amounts of strongly and moderately acidic sites $\left(0.446 \mathrm{mmol} \mathrm{H}^{+} \mathrm{g}^{-1}\right)$, associated with Nafion sulfonic groups, and a moderate amount of weakly acidic sites (0.904 mmol $\mathrm{H}^{+} \mathrm{g}^{-1}$ ), probably derived from surface silanol groups on porous silica framework. The SBA-15-conv catalyst only contains weakly acidic sites $\left(1.66 \mathrm{mmol} \mathrm{H}^{+} \mathrm{g}^{-1}\right)$, associated with surface silanol groups. In addition a large amount of surface silanol groups as weakly acidic sites $\left(1.59 \mathrm{mmol} \mathrm{\textrm {H } ^ { + }} \mathrm{g}^{-1}\right)$, the unconventional SBA-15-p catalyst contains around $0.557 \mathrm{mmol} \mathrm{H}^{+} \mathrm{g}^{-1}$ of strongly and moderately acidic sites, which are close to the amount of superficial $\mathrm{Zr}^{4+}$ clusters $\left(0.61 \mathrm{mmol} \mathrm{Zr} \mathrm{g}^{-1}\right)$. For the unconventional 5-25SA-SBA-15-p catalysts, the weakly acidic sites of surface silanol groups are nearly the same (1.48-1.59 mmol $\mathrm{H}^{+} \mathrm{g}^{-1}$ ) whereas the strongly and moderately acidic sites are increased to $0.709-0.962 \mathrm{mmol} \mathrm{H}^{+} \mathrm{g}^{-1}$, due to the coexistence of superficial $\mathrm{Zr}^{4+}$ clusters and propylsulfonic groups. Note that that the strongly and moderately acidic sites are slightly lower than the $\mathrm{Zr}$ and $\mathrm{S}$ loadings (Table 1). It suggests that a portion of superficial $\mathrm{Zr}^{4+}$ clusters and propylsulfonic groups is probably inaccessible [29]. 


\subsection{Synthesis of Jatropha BDF}

The transesterification of CJO with methanol was performed in a batch-type high pressure stainless steel reactor at $200{ }^{\circ} \mathrm{C}$ and autogeneous pressure. According to the GC-MS analysis, the targeting product is FAME and the unwanted byproducts are mostly DG, MG and FFA. Fig. 8 illustrates the transesterification of CJO with methanol over the unconventional 15SA-SBA-15-p catalyst as a function of reaction time at 200 ${ }^{\circ} \mathrm{C}$. The methanol-to-CJO molar ratio and the catalyst-to-CJO weight percentage were kept at 27 and 15, respectively. Based on the requirement of the EN 14214 standard, the composition of BDF as a function of reaction time is represented by the mass fraction. The quantitative analysis shows that the FAME content is promptly increased to 80.8 wt $\%$ in the first $1 \mathrm{~h}$, reached a maximum value of $83.1 \mathrm{wt} \%$ at $2 \mathrm{~h}$, and then gradually decreased to $75.0-79.5 \mathrm{wt} \%$ at 3-4 $\mathrm{h}$. On the contrary, the unreactive TG content is quickly dropped to $4.6 \mathrm{wt} \%$ in the first $1 \mathrm{~h}$ and then progressively reduced to $0.21 \mathrm{wt} \%$ at $4 \mathrm{~h}$. The parallel products of DG and MG are around 1.2-5.0 wt\%, slightly varied with the reaction period. The byproduct of $G$ is always lower than $0.5 \mathrm{wt} \%$, suggesting that G can be completely removed by discarding method. Noteworthily, the unwanted 
byproduct of FFA is lower than $5.0 \mathrm{wt} \%$ at $1 \mathrm{~h}$, and then significantly increased to 8.6-18.6 wt\% as the reaction times are prolonged to $2-4 \mathrm{~h}$. When the commercial sulfonic acids of SAC-13 and Amberlyst-15 are used as solid acid catalysts, the unwanted byproduct of FFA is further increased to 24.4-29.6 wt\% whereas the FAME contents are reduced to 59.2-73.2 wt\% (Fig. S5, ESI). The FFA and unwanted byproducts are probably formed by dehydration of methanol into ether and water, and subsequent hydrolysis of glycerides and FAME with water catalyzed by strongly acidic sites if the reaction time is enlarged [22].

Table 1 compares the activities of the unconventional 5-25SA-SBA-15-p and reference catalysts in Jatropha BDF synthesis at $200{ }^{\circ} \mathrm{C}$ for $1 \mathrm{~h}$. Based on the requirement of EN 14105 standard, the amounts of glycerides and glycerol are conversed into the $G_{T}$ value by the equation (1) as described in section 2.4. For the blank test and the SBA-15-conv catalyst, the FAME, FFA and $\mathrm{G}_{\mathrm{T}}$ contents are 7.2-7.3, 3.5 and $10 \mathrm{wt} \%$, respectively. Apparently, the mesoporous silica framework has almost no activity in Jatropha BDF synthesis. The FAME content over the unconventional SBA-15-p catalyst with superficial $\mathrm{Zr}^{4+}$ clusters as a solid Lewis acid is enhanced to 51.2 wt\% accompanying with a high $\mathrm{G}_{\mathrm{T}}$ value of $6.8 \mathrm{wt} \%$. It suggests that the superficial $\mathrm{Zr}^{4+}$ clusters are effective in catalyzing Jatropha BDF synthesis. Melero et al. 
lately reported that the Zr-incorporated SBA-15 material agglomerated with bentonite was an efficient solid catalyst in transformation of waste cooking oil into high-quality $\mathrm{BDF}$ at relatively high temperature and pressure $\left(210{ }^{\circ} \mathrm{C}\right.$ and 70 bar) [49]. Although the FAME content can be slightly enhanced if the reaction time for the SBA-15-p catalyst is enlarged (Table S3, ESI), the long reaction time not only consumes more energy but also promotes the hydrolysis of TG and FAME toward FFA. The resultant BDF products become dark yellow or brown, implying that the oligomers with poorly cold flow property are formed. When the unconventional 5-25SA-SBA-15-p catalysts with propylsulfonic groups and superficial $\mathrm{Zr}^{4+}$ clusters are applied as mixed solid Bronsted and Lewis acids in Jatropha BDF synthesis, the FAME contents are significantly increased to around 73.5-80.8 wt\% accompanying with low $\mathrm{G}_{\mathrm{T}}$ values of around 1.7-3.2 wt\%. The FFA values are slightly increased to around 3.3-7.9 wt\%, proportional to the loadings of propylsulfonic groups. It is apparent that the propylsulfonic groups in the unconventional 5-25SA-SBA-15-p catalysts speed up the transesterification rate but also slightly promote unwanted reactions. Among them, the 15SA-SBA-15-p catalyst containing proper amounts of propylsulfonic groups $\left(1.15 \mathrm{mmol} \mathrm{g}^{-1}\right)$ and superficial $\mathrm{Zr}^{4+}$ clusters $\left(0.66 \mathrm{mmol} \mathrm{g}^{-1}\right)$ gives highest FAME content with low concentrations of unwanted FFA and byproducts in Jatropha BDF synthesis. 
For the commercial sulfonic resins of Amberlyst-15 and SAC-13 as solid Bronsted acids, the FAME and FFA contents are around 48.8-70.0 wt\% and 13-25 wt\%, respectively. The Amberlyst-15 catalyst with a larger amount of phenylsulfonic groups gives higher FAME and FFA contents. However, the abnormal high FFA contents of the Amberlyst-15 and SAC-13 catalysts indicate that the phenylsulfonic and Nafion sulfonic groups are favorable for the hydrolysis of FAME and TG toward FFA and byproducts.

\subsection{Optimization of reaction condition}

In order to control the hydrolysis of TG and FAME toward FFA catalyzed by strongly acidic sites, it is necessary to optimize the reaction temperature and time. Under $150-175{ }^{\circ} \mathrm{C}$, the maximum FAME contents over the unconventional 15SA-SBA-15-p catalyst are decreased to 70.0-75.4 wt\% and more unwanted FFA and byproducts are formed because of long reaction times (Table S3 and Fig. 6, ESI). As mentioned above, the long reaction time also makes the hydrolysis of FAME toward FFA more at $200{ }^{\circ} \mathrm{C}$. For the purpose of achieving high FAME content with low concentrations of unwanted FFA and byproducts, the reaction temperature and time are 
optimized at $200{ }^{\circ} \mathrm{C}$ for $1 \mathrm{~h}$ hereafter.

The Jatropha BDF synthesis over the unconventional 15SA-SBA-15-p catalyst was further examined by varying the methanol-to-CJO molar ratio and catalyst weight. Fig. 9 shows the influence of the methanol-to-CJO molar ratio on the activity of the unconventional 15SA-SBA-15-p catalyst in Jatropha BDF synthesis at $200{ }^{\circ} \mathrm{C}$ for $1 \mathrm{~h}$. The catalyst weight was kept at $15 \mathrm{wt} \%$ of CJO. Because the transesterification of CJO with methanol into Jatropha BDF can be driven by adding more methanol, the Jatropha FAME content is slightly enhanced from 79.7 to $82.6 \mathrm{wt} \%$ when the methanol-to-CJO molar ratio is increased from 14 to 23 . With high methanol-to-oil molar ratios of $34-55$, the Jatropha FAME contents are declined to 68.2-75.6 wt\% whereas the unreactive TG contents are increased to 11.8-18.9 wt\%. Similar phenomenon is observed when the Amberlyst-15 catalyst is used (Fig. S7, ESI). Evidently, the dilution of the CJO concentration by an excess of methanol decreases the forward transesterication rate. Fig. 10 shows the influence of catalyst weight on the activity of the unconventional 15SA-SBA-15-p catalyst in Jatropha BDF synthesis at $200{ }^{\circ} \mathrm{C}$ for $1 \mathrm{~h}$. The methanol-to-CJO molar ratio was kept at 23. The Jatropha FAME contents are gradually increased to 82-83 wt\% when the catalyst weights are equal to or higher than $15 \mathrm{wt} \%$ of CJO. However, an increase of FFA by increasing the catalyst weight is observed. To 
prevent high concentrations of unwanted FFA and byproducts, the Jatropha BDF synthesis over the unconventional 15SA-SBA-15 catalyst are carried out by an methanol-to-CJO molar ratio of 23 and an catalyst-to-CJO weight percentage of 15 hereafter.

\subsection{Reaction mechanisms}

The proposed reaction mechanisms for Jatropha BDF synthesis over the unconventional 5-25SA-SBA-15-p catalysts as mixed solid Bronsted and Lewis acids are illustrated in Scheme 2. The simplified ester of $\mathrm{R}_{2} \mathrm{COOR}_{1}$ represents the starting TG molecule, where $R_{1}$ is the glycerol part and $R_{2}$ is the fatty acid tail. When the BDF synthesis is catalyzed by the solid Lewis acid site, the Lewis complex of intermediate (III) is formed through the coordination of the starting ester on the superficial $\mathrm{Zr}^{4+}$ cluster (I), and subsequent nucleophilic attacking of the carbonyl group of the intermediate (II) by methanol. Then, a new ester of $\mathrm{CH}_{3} \mathrm{COOR}_{2}$, i.e. FAME, is formed by back donating of the electron pair on C-O to carbon, and desorbed from the

superficial $\mathrm{Zr}^{4+}$ cluster for the next catalytic cycle. When the BDF synthesis is catalyzed by the solid Bronsted acid site, the carbonyl group of the starting ester is protonated by 
the propylsulfonic group (IV) to form the intermediate (V), followed by nucleophilic attacking by methanol to form a tetrahedral intermediate (VI). FAME is then formed by the hydrogen migration and the breakdown of the intermediate (VI) for the next reaction cycle.

The catalytic study has demonstrated that both types of solid Lewis and Bronsted acids are able to catalyzed Jatropha BDF synthesis, and their intrinsically acidic nature has a great influence on the composition of BDF. The unconventional 15SA-SBA-15-p catalyst as a mixed solid Bronsted and Lewis acid gives a highest activity in BDF synthesis with minimum byproducts because of its proper loading of propylsulfonic groups $\left(1.15 \mathrm{mmol} \mathrm{g}^{-1}\right)$ and superficial $\mathrm{Zr}^{4+}$ clusters $\left(0.66 \mathrm{mmol} \mathrm{g}^{-1}\right)$ with suitable different heat of $\mathrm{NH}_{3}$ adsorption in the range of $90-135 \mathrm{mmol} \mathrm{g}^{-1}$. It is specially noticed that the FAME, FFA and $\mathrm{G}_{\mathrm{T}}$ contents in Jatropha BDF synthesis are closely correlated to the loading, distribution and acidic strength of sulfonic groups. Because the propylsulfonic groups are insufficient, the unconventional 5-10SA-SBA-15-p catalysts give lower FAME contents accompanying with higher $\mathrm{G}_{\mathrm{T}}$ contents. The unconventional 20-25SA-SBA-15-p catalysts show lower FAME contents accompanying with higher FFA and $\mathrm{G}_{\mathrm{T}}$ contents, suggesting that the side reactions toward unwanted byproducts are probably driven by the aggregated sulfonic acids at high loadings [32,50]. On the other 
hand, commercial sulfonic resin of Amberlyst-15 as a solid Bronsted acid is superior to the unconventional SBA-15-p catalyst with superficial $\mathrm{Zr}^{4+}$ clusters as a solid Lewis acid in catalyzing Jatropha BDF synthesis. Unfortunately, the strongly acidic nature of phenylsulfonic groups is favorable for the hydrolysis of FAME and TG toward FFA.

\subsection{Influences of FFA and water}

Table 2 compares the influences of lauric acid (LA) and water on the activities of the unconventional 15SA-SBA-15-p and reference catalysts in Jatropha BDF synthesis. Note that the LA and water contents in CJO are lower than $0.01 \mathrm{wt} \%$ and $500 \mathrm{ppm}$, respectively. When the amount of LA added to the reaction medium is $50 \mathrm{wt} \%$ of CJO, the LA conversions over the unconventional 15SA-SBA-15-p and SAC-13 catalysts are around 93-96\% and the FAME contents remain unchanged. By contrary, the LA conversion over the Amberlyst-15 catalyst is only 62\% and the FAME content is slightly decreased to $68 \mathrm{wt} \%$. This results suggest that the sulfonic groups incorporated in the hydrophilic silica frameworks of the unconventional 15SA-SBA-15-p and SAC-13 catalysts have stronger resistance to FFA than those incorporated in the hydrophobic organic framework of the Amberlyst-15 catalyst. On the other hand, the 
FAME content over the unconventional 15SA-SBA-15-p catalyst is slightly decreased from 83 to 78 wt\% when the amount of water added to the reaction medium is $5 \mathrm{wt} \%$. For the SAC-13 and Amberlyst-15 catalysts, the FAME contents are significantly dropped about $13-16 \%$ by adding equal amount of water (also see Fig. S8, ESI). The high water tolerance level of the unconventional 15SA-SBA-15-p catalyst is related to its largely hydrophilic surface as a good medium for the adsorption of water.

\subsection{Synthesis of BDFs derived from various vegetable oils}

The unconventional 15SA-SBA-15-p catalyst has ability to transform a great diversity of vegetable oils, including refined soybean oil (RSO), refined rapeseed oil (RRO), waste cooking oil (WCO), CJO, crude palm oil (CPO) and palm fatty acid distillates (PFAD), into BDFs at $200{ }^{\circ} \mathrm{C}$ and autogeneous pressure. Fig. 11 shows that the FAME contents increase in the follow manner: RSO $<$ WCO $<$ RRO $<$ CJO $<$ CPO

$<$ PEAD. The variation in FAME contents is almost in the same trend as the changes in the acid values of various vegetable oils. It is due to that the esterification rate is higher than transesterification rate when the solid acids are used as catalysts. Based on the results mentioned above, the transformation of various vegetable oils with a wide range 
of acid value into BDF can be completely catalyzed by the unconventional 15SA-SBA-15-p catalyst in a relatively short time.

\subsection{Regeneration}

The used 15SA-SBA-15-p catalyst was regenerated by ethanol extraction at $78{ }^{\circ} \mathrm{C}$ for 1 day in order to completely remove the unreactive TG, unwanted byproducts or cokes from the pore surfaces [30]. The regenerated 15SA-SBA-15-p catalyst was used again in Jatropha BDF synthesis at $200{ }^{\circ} \mathrm{C}$ and autogenous pressure, in comparison with the regenerated SAC-13 and Amberlyst-15 catalysts. Table 3 shows that the FAME contents over the unconventional 15SA-SBA-15-p catalysts after the first and second regenerations are slightly decreased to 82.2 and $81.2 \mathrm{wt} \%$, respectively. The regeneration process has a little influence on the structural property and morphology of the unconventional 15SA-SBA-15-p catalyst, except the acid capacity (Figs. 2(b and d), S9 and S10, ESI). The sulfur analysis shows that the Jatropha BDF samples synthesized by fresh and regenerated 15SA-SBA-15-p catalysts contain around 2.4-5.5 ppm of sulfur. It suggests that the loss of acid capacity is associated with the leaching of propylsulfonic groups from the unconventional 15SA-SBA-15-p catalyst during the 
Jatropha BDF synthesis. However, it should be noticed that the leaching of the unconventional 15SA-SBA-15-p catalyst is very little as compared with the conventional sulfonic acid-functionalized SBA-15 materials in the literature reports [26,30,31]. The unconventional 15SA-SBA-15-p catalyst is synthesized with the aid of highly solvated $\mathrm{Zr}^{4+}$ ions, where the salting-out property of $\mathrm{Zr}^{4+}$ ions not only reduces the critical micelle concentration of P123 triblock copolymer but also increases the interaction of TEOS around P123 micelles [33]. As a result, the structural regularity and stability of the unconventional 15SA-SBA-15-p catalyst are higher than those of conventional sulfonic acid-functionalized SBA-15 materials [51].

The FAME contents over the regenerated Amberlyst-15 and SAC-13 catalysts are dropped to 65.1-66.3 and 28.4-34.5 wt\%, respectively, due to that the structural property and acid capacity are significantly influenced by the regeneration. For the regenerated SAC-13 catalyst, the structural property and acid capacity are seriously decreased after the first regeneration and remained unchanged thereafter. The sulfur analysis shows that the Jatropha BDF samples contain around 3.7-4.5 ppm of sulfur even through the fresh and regenerated SAC-13 catalysts have relatively low amounts of Nafion sulfonic groups. For the regenerated Amberlyst-15 catalysts, the $\mathrm{S}_{\mathrm{BET}}$ and $\mathrm{V}_{\text {total }}$ values are gradually increased by the number of the regeneration whereas the $\Phi_{\mathrm{p}}$ value shows an 
opposite trend. The sulfur analysis shows that the sulfur contents of Jatropha BDF samples synthesized by fresh and regenerated Amberlyt-15 catalysts are significantly increased to 37-97 ppm. It is evident that the polystyrene framework of the Amberlyst-15 catalyst is thermally unstable and undergoes structural shrinkage and carbonization during the Jatropha BDF synthesis.

\section{Conclusions}

The comprehensively structural and catalytic characterizations gave us new insights into the intrinsically acidic nature of the unconventional 5-25SA-SBA-15-p catalysts with superficial $\mathrm{Zr}^{4+}$ clusters and propylsulfonic groups, and their catalytic behavior in transformation of non-edible vegetable oils with various acid values, such as Jatropha oil, into BDF as a renewable transportation fuel. The results were compared with those of the SBA-15-conv catalyst without any Lewis and Bronsted acids, the unconventional SBA-15-p catalyst with superficial $\mathrm{Zr}^{4+}$ clusters as a pure solid Lewis acid, and commercial sulfonic resins of Amberlyst-15 and SAC-13 with phenylsulfonic and Nafion sulfonic groups as solid Bronsted acids. The SBA-15-conv catalyst without any Lewis and Bronsted acids had almost no activity in Jatropha BDF synthesis. The 
unconventional SBA-15-p catalyst gave a moderate FAME content accompanying with a large $G_{T}$ value. In the presence of propylsulfonic groups, all the unconventional 5-25SA-SBA-15-p catalysts were highly active in Jatropha BDF synthesis. Among them, the unconventional 15SA-SBA-15-p catalyst gave a highest FAME content with minimum byproducts, due to its proper loading and acidic strength of superficial $\mathrm{Zr}^{4+}$

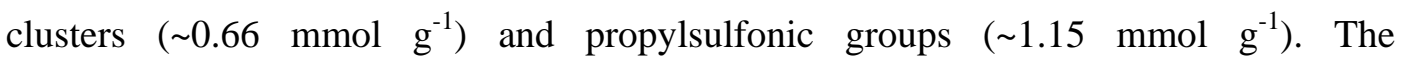
unconventional 5-10SA-SBA-15-p catalysts with insufficient amounts of propylsulfonic groups showed relatively low FAME contents accompanying with relatively high $\mathrm{G}_{\mathrm{T}}$ values. On the contrary, the unconventional 20-25SA-SBA-15-p catalysts with excess amounts of propylsulfonic groups gave slightly low FAME contents accompanying with relatively high FFA and $\mathrm{G}_{\mathrm{T}}$ values. The Amberlyst-15 and SAC-13 catalysts with strongly acidic strengths were favorable for the hydrolysis of TG and FAME toward unwanted FFA and byproducts, resulting in low-quality BDF products. Furthermore, the quickly deactivation by water, FFA and regeneration was observed due to the poison and leaching of sulfonic groups and the decomposition of thermally unstable framework. 


\section{Acknowledgments}

The financial support from JST-JICA's SATREPS project is gratefully acknowledged. Chen would like to thank Dr. A. Endo and Dr. A. Kawai of Research Institute for Innovation in Sustainable Chemistry, AIST, for the XRD measurement, Dr.

Y. Miseki and Dr. K. Sayama of Energy Technology Research Institute, AIST, for the UV-Vis experiment, and Dr. M. Oguma of Energy Technology Research Institute, AIST, for the ICP-OES analysis. 


\section{References}

[1] J. A. Melero, J. Iglesias, G. Morales, Green Chemistry 11 (2009) 1285-1308.

[2] K. Wilson, A.F. Lee, Catalysis Science and Technology 2 (2012) 884-897.

[3] Department of Alternative Energy Development and Efficiency, The Renewable and Alternative Energy Development Plan for 25 Percent in 10 Years (AEDP 2012-21); $\quad$ www.dede.go.th/dede/images/stories/dede aedp 2012 2021.pdf, (accessed September 11, 2013)

[4] M. D. Serio, R. Tesser, L. Pengmei, E. Santacesaria, Energy and Fuel 22 (2008) 207-217.

[5] E. Santacesaria, G. M. Vicente, M. D. Serio, R. Tesser, Catalysis Today 195 (2012) $2-13$.

[6] L. Bournay, D. Casanave, B. Delfort, G, Hillion, J.A. Chodorge, Catalysis Today 106 (2005) 190-192.

[7] R. Stern, G. Hillion, J. J. Rouxel, S. Leporq, United States Patent 5,908,946 (1999).

[8] H. J. Berchmans, S. Hirata, Bioresource Technology 99 (2008) 1716-1721.

[9] Z. Helwani, M.R. Othman, N. Aziz, W.J.N. Fernando, J. Kim, Fuel Processing Technology 90 (2009) 1502-1514.E.

[10]Lotero, Y. Liu, D.E. Lopez, K. Suwannakarn, D.A. Bruce, J.G. Goodwin, Industrial 
\& Engineering Chemistry Research 44 (2005) 5353-5363.

[11]D.E. Lopez, J.G. Goodwin, D.A. Bruce, E. Lotero, Applied Catalysis A: General 295 (2005) 97-105.

[12]I.K. Mbaraka, B.H. Shanks, Journal of the American Oil Chemists' Society 83 (2006) 79-91.

[13]D.E. Lopes, J.G. Goodwin, D.A. Bruce, Journal of Catalysis 245 (2007) 381-391.

[14]F. Liu, A. Zheng, I. Noshadi, F.S. Xiao, Applied Catalysis B: Environmental 136-137 (2013) 193-201.

[15]B. Hamad, R.O. Lopes de Souza, G. Sapaly, M.G. Carneiro Rocha, P.G. Pries de Oliveira, W.A. Gonzalez, E. Andrade Sales, N. Essayem, Catalysis Communications 10 (2008) 92-97.

[16]S. Ramu, N. Linagaiah, B.L.A. Prabhvathi Devi, R.B.N. Prasad, I. Suryanarayana, P.S. Sai Prasad, Applied Catalysis A: General 276 (2004) 163-168.

[17]S. Furuta, H. Matsuhashi, K. Arata, Catalysis Communications 5 (2004) 721-723.

[18]C.M. Garcia, S. Teixeira, L.L. Marcinuiuk, U. Schuchardt, Bioresource Technology 99 (2008) 6608-6613.

[19]J.A. Melero, L.F. Bautisa, J. Iglesias, G. Morales, R. Sanchez-Vazquez, Catalysis Today 195 (2012) 44-53. 
[20]T. Suzuta, M. Toba, Y. Abe, Y. Yoshimura, Journal of the American Oil Chemists' Society 89 (2012) 1981-1989.

[21]S.Y. Chen, T. Mochizuki, Y. Abe, M. Toba, Y. Yoshimura, Catalysis Communications 41 (2013) 136-139.

[22]S.Y. Chen, T. Mochizuki, Y. Abe, M. Toba, Y. Yoshimura, Applied Catalysis B: Environmental 148-149 (2014) 344-356.

[23]I.K. Mbaraka, D.R. Radu, V.S.Y. Lin, B.H. Shanks, Journal of Catalysis 219 (2003) 329-336.

[24]Y. Liu, E. Lotero, J.G. Goodwin, Journal of Catalysis 242 (2006) 278-286.

[25]Y. Liu, E. Lotero, J. G. Goodwin, Journal of Catalysis 243 (2006) 221-228.

[26]J.A. Melero, L. Fernando Bautista, G. Morales, J. Iglesias, R. Sanchez-Vazquez Chemical Engineering Journal 161 (2010) 323-331.

[27]G. Morales, L. Fernando Bautista, J.A. Melero, J. Iglesias, R. Sanchez-Vazquez, Bioresource Technology 102 (2011) 9571-9578.

[28]A. Macario, G. Giordano, Catalysis Letter 143 (2013) 159-168.

[29] S.Y. Chen, T. Yokoi, C.Y. Tang, L.Y. Jang, T. Tatsumi, J.C.C. Chan, S. Cheng, Green Chemistry 13 (2011) 2920-2930.

[30]A.C. Alba-Rubio, F. Vila, D.M. Alonso, M. Ojeda, R. Mariscal, M.L. Granados, 
Applied Catalysis B: Environmental 95 (2010) 279-287.

[31]D. Zuo, J. Lane, D. Culy, M. Schultz, A. Pullar, M. Waxman, Applied Catalysis B: Environmental 129 (2013) 342-350.

[32]S.Y. Chen, S. Lao-ubol, T. Mochizuki, Y. Abe, M. Toba, Y. Yoshimura, Bioresource Technology 57 (2014) 346-350.

[33]S.Y. Chen, C.Y. Tang, W.T. Chuang, J.J. Lee, Y.L. Tsai, J.C.C. Chan, C.Y. Lin, Y.C. Liu, S Cheng, Chemistry of Materials 20 (2008) 3906-3916.

[34]K. A. Shah, J. K. Parikh, K. C. Maheria, Res. Chem. Intermed. (2013), DOI 10.1007s/11164-013-1253-6.

[35]D. A. Kotadia, S. S. Soni, Monatsh. Chem. 144 (2013) 1735-1741.

[36]D. Zhao, J. Feng, Q. Huo, N. Melosh, G. H. Fredrickson, B. F. Chmelka, G. D. Stucky, Science 279 (1998) 548-552.

[37]S.Y. Chen, Y.T. Chen, J.J. Lee, S. Cheng, Journal of Materials Chemistry 21 (2011) 5693-5703.

[38]W.W. Lukens, P. Schmidt-Winkel, Z. Zhao, J. Feng, G.D. Stucky, Langmuir 15 (1999) 5403-5409.

[39] S.Y. Chen, C.Y. Huang, T. Yokoi, C.Y. Tang, S.J. Huang, J.J. Lee, J. C. C. Chan, T. Tatsumi, S. Cheng, Journal of Materials Chemistry 22 (2012) 2233-2243. 
[40]X. Wang, S. Cheng, J.C.C. Chan, Journal of Physical Chemistry C 111 (2007) 2156-2164.

[41]C.C. Chen, S. Cheng, L.Y. Jang, Microporous and Mesoporous Materials 109 (2008) 258-270.

[42] S.Y. Chen, L.Y. Jang, S. Cheng, Chemistry of Materials 16 (2004) 4174-4180

[43] S.Y. Chen, J.F. Lee, S. Cheng, Journal of Catalysis 270 (2010) 196-205.

[44]E.P. Parry, Journal of Catalysis 2 (1963) 371-379.

[45]N.Y. Topsoe, F. Joensen, E.G. Derouane, Journal of Catalysis 110 (1988) 404-406.

[46]G. A. Eimer, S.G. Casuscelli, C.M. Chanquia, V. Elias, M.E. Crivello, E.R. Herrero, Catalysis Today 133-135 (2008) 639.

[47]T. Mochizuki, S.Y. Chen, M. Toba, Y. Yoshimura, Applied Catalysis B: Environmental 146 (2014) 237-243.

[48]T. Liu, Z. Li, W. Li, C. Shi, Y. Wang, Bioresource Technology 133 (2013) 618-621.

[49]J.A. Melero, L.F. Bautista, J. Iglesias, G. Moralesa, R. Sánchez-Vazquezaa, Applied Catalysis B: Environmental 145 (2014) 197-204.

[50]J.P. Dacquin, H. E. Cross, D.R. Brown, T. Duren, J.J. Williams, A.F. Lee, K. Wilson, Green Chemistry 12 (2010) 1383-1391.

[51]Y. Usami, T. Hongo, A. Yamazaki, Journal of Porous Materials 19 (2012) 897-902. 
Table 1. The structural and acid properties of the unconventional 5-25SA-SBA-15-p and reference catalysts, and their catalytic activities in Jatropha BDF synthesis. ${ }^{a}$

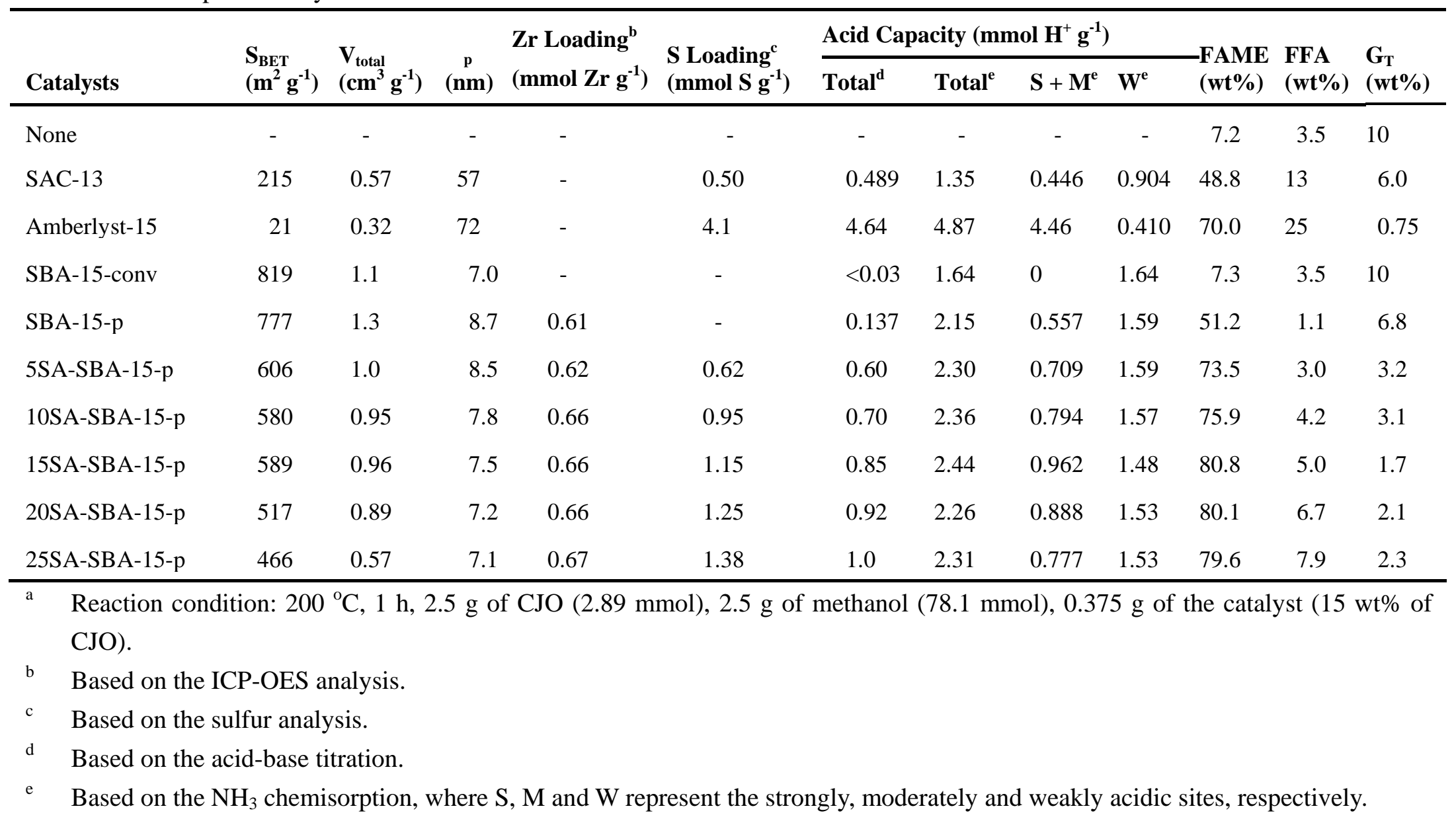


Table 2. Influences of LA and water on the activities of the unconventional 15SA-SBA-15-p and reference catalysts in Jatropha BDF synthesis. $^{\text {a }}$

\begin{tabular}{|c|c|c|c|c|c|c|}
\hline Catalysts & $\begin{array}{l}\text { Water/CJO } \\
\text { (wt\%) }\end{array}$ & $\begin{array}{l}\text { LA/CJO } \\
\text { (wt \%) }\end{array}$ & $\begin{array}{l}\text { LA Conv. } \\
(\%)\end{array}$ & $\begin{array}{l}\text { FAME }^{b} \\
(w t \%)\end{array}$ & $\begin{array}{l}\text { FFA }^{b} \\
(w t \%)\end{array}$ & $\begin{array}{l}G_{T}^{b} \\
(w t \%)\end{array}$ \\
\hline \multirow[t]{3}{*}{ 15SA-SBA-15-p } & - & - & - & 83 & 5.9 & 1.8 \\
\hline & - & 50 & 96 & 82 & 11 & 1.5 \\
\hline & 5 & - & - & 78 & 8.9 & 2.4 \\
\hline \multirow[t]{3}{*}{ Amberlyst-15 } & - & - & - & 70 & 25 & 0.75 \\
\hline & - & 50 & 62 & 68 & 26 & 1.0 \\
\hline & 5 & - & - & 61 & 33 & 1.2 \\
\hline \multirow[t]{3}{*}{ SAC-13 } & - & - & - & 45 & 7.6 & 6.0 \\
\hline & - & 50 & 93 & 45 & 8.6 & 6.9 \\
\hline & 5 & - & - & 38 & 6.2 & 6.8 \\
\hline
\end{tabular}

a Reaction condition: $200{ }^{\circ} \mathrm{C}$ for $1 \mathrm{~h}$ under autogenous pressure, $2.5 \mathrm{~g}(2.80 \mathrm{mmol})$ of $\mathrm{CJO}, 2.13 \mathrm{~g}(66.5 \mathrm{mmol})$ of methanol, $0.375 \mathrm{~g}$ of the catalyst (15 wt\% of CJO).

b Based on the EN 14103 and 14105 methods. 
Table 3. Effect of regeneration on the activities of the unconventional 15SA-SBA-15-p and reference catalysts in Jatropha BDF synthesis. ${ }^{\mathrm{a}}$

\begin{tabular}{|c|c|c|c|c|c|c|c|}
\hline Catalysts & No. of Regeneration & $\begin{array}{l}\begin{array}{l}S_{\text {BET }} \\
\left(m^{2} g^{-1}\right)\end{array} \\
\end{array}$ & $\begin{array}{l}V_{\text {total }} \\
\left(\mathrm{cm}^{3} \mathrm{~g}^{-1}\right) \\
\end{array}$ & $\begin{array}{c}\mathrm{p} \\
(\mathrm{nm}) \\
\end{array}$ & $\begin{array}{l}\text { Acid Capacity } \\
\left(\mathrm{mmol} \mathrm{H}^{+} \mathrm{g}^{-1}\right)\end{array}$ & $\begin{array}{l}\text { FAME }^{b} \\
(\mathrm{wt} \%) \\
\end{array}$ & $\begin{array}{l}\text { Leaching of S } \\
\text { (ppm) }\end{array}$ \\
\hline \multirow[t]{3}{*}{ 15SA-SBA-15-p } & Fresh & 589 & 0.96 & 7.5 & 2.47 & 82.6 & 5.5 \\
\hline & 1 & 564 & 0.93 & 7.7 & 2.14 & 82.2 & 2.4 \\
\hline & 2 & 559 & 0.93 & 7.6 & 1.95 & 81.2 & 2.4 \\
\hline \multirow[t]{3}{*}{ Amberlyst-15 } & Fresh & 21 & 0.32 & 72 & 4.87 & 70.0 & 97 \\
\hline & 1 & 36 & 0.34 & 37 & 4.25 & 66.3 & 82 \\
\hline & 2 & 57 & 0.55 & 45 & 3.69 & 65.1 & 37 \\
\hline \multirow[t]{3}{*}{ SAC-13 } & Fresh & 215 & 0.57 & 57 & 1.35 & 48.8 & 4.5 \\
\hline & 1 & 163 & 0.58 & 32 & 1.07 & 34.5 & 4.7 \\
\hline & 2 & 161 & 0.61 & 32 & 1.00 & 28.4 & 3.7 \\
\hline
\end{tabular}

c Reaction condition: $200{ }^{\circ} \mathrm{C}$ for $1 \mathrm{~h}$ under autogenous pressure, $2.5 \mathrm{~g}(2.80 \mathrm{mmol})$ of $\mathrm{CJO}, 2.13 \mathrm{~g}(66.5 \mathrm{mmol})$ of methanol, $0.375 \mathrm{~g}$ of the regenerated catalyst (15 wt\% of CJO).

d Based on the EN 14103 and 14105 methods. 


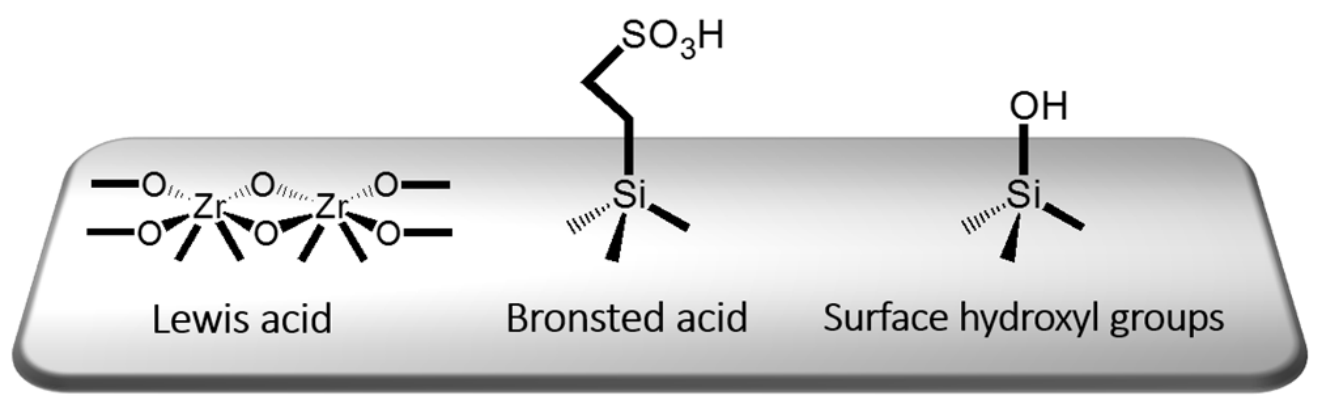

Scheme 1. Illustration of various acidic sites incorporated on the unconventional 5-25SA-SBA-15-p catalysts. 
(a)
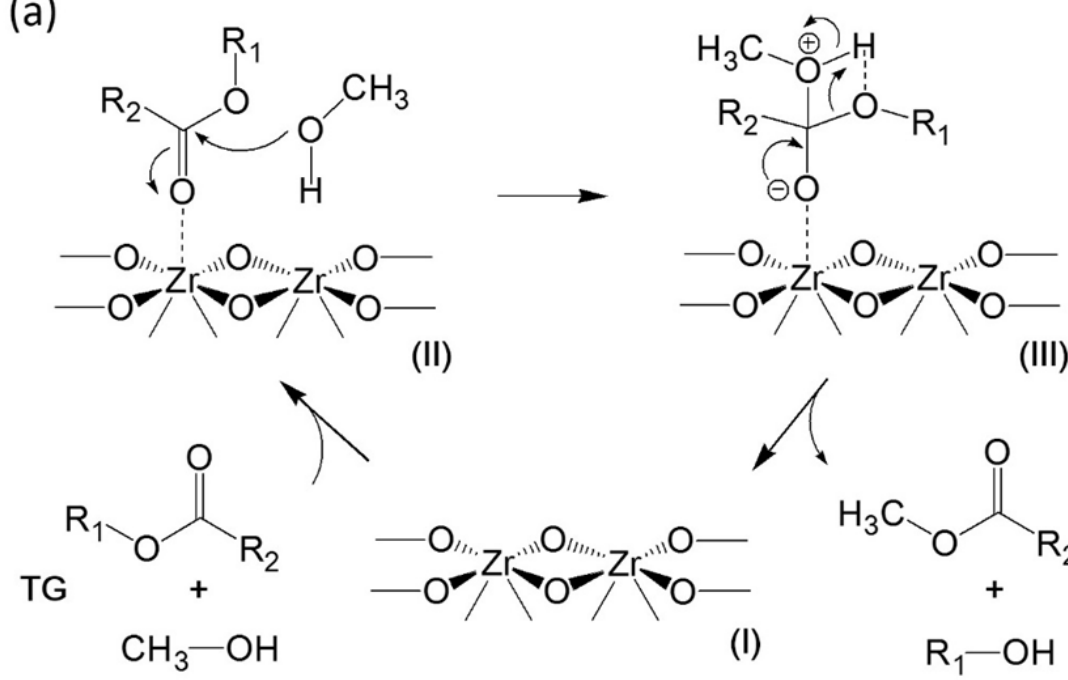

(III)

Superficial $\mathrm{Zr}^{4+}$ cluster

as a Lewis acid site

(b)

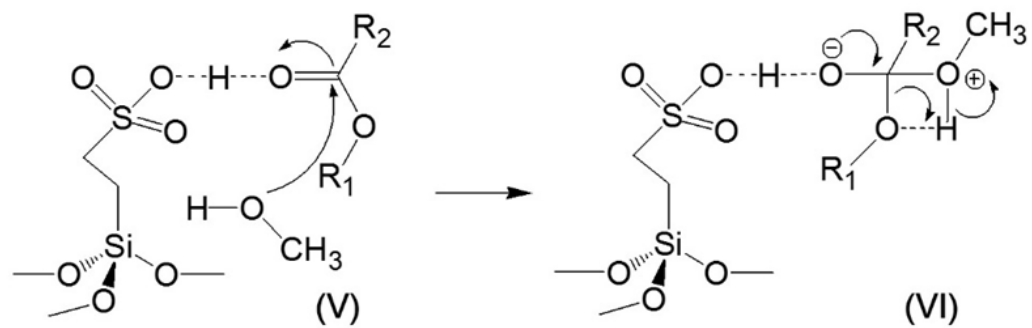<smiles></smiles>
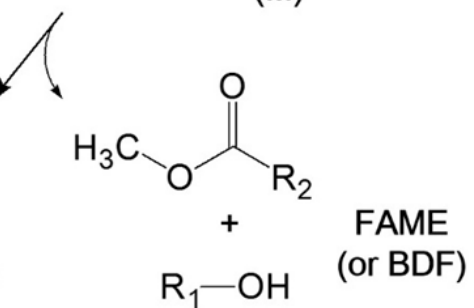

(I)

$$
\mathrm{R}_{1}-\mathrm{OH}
$$

(VI)
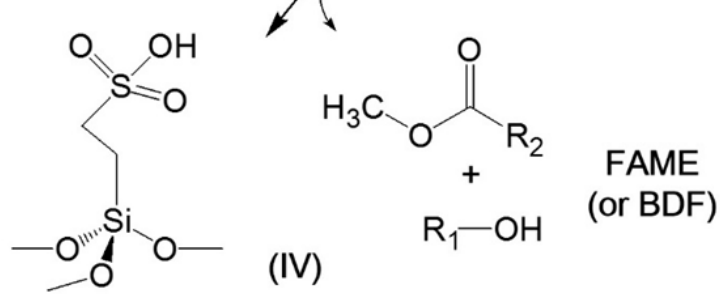

Propylsulfonic acid as a Bronsted acid site

Scheme 2. Proposed reaction mechanisms for Jatropha BDF synthesis over (a) Lewis acid site and (b) Bronsted acid site of the unconventional 5-25SA-SBA-15-p catalysts. 

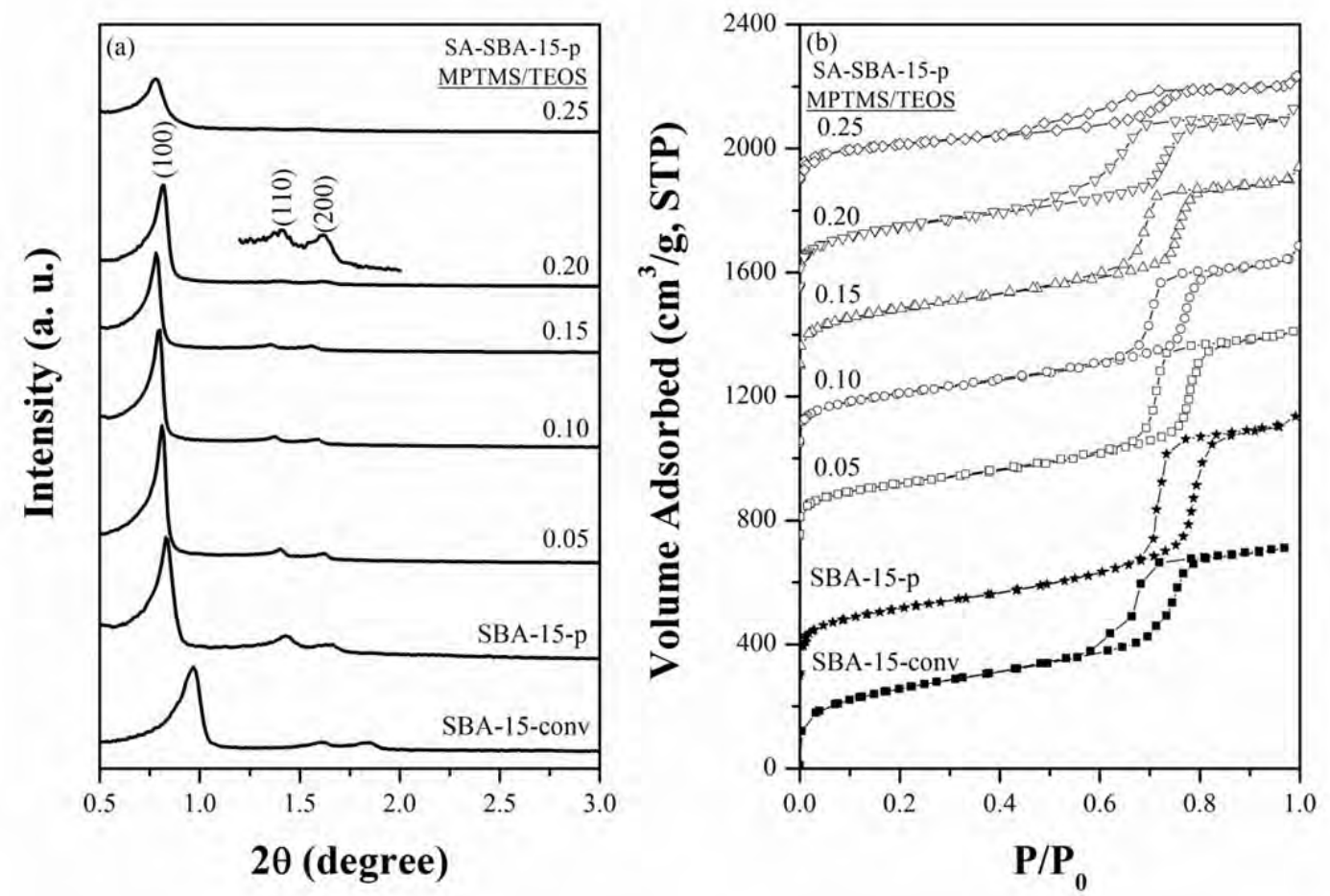

Fig. 1. (a) small-angle XRD patterns and (b) $\mathrm{N}_{2}$ adsorption-desorption isotherms of the calcined SBA-15-conv, calcined SBA-15-p and unconventional 5-25SA-SBA-15-p catalysts. The isotherms are shifted by $0,300,750,1000,1250,1600$ and $1800 \mathrm{~cm}^{3} \mathrm{~g}^{-1}$ STP, respectively. 

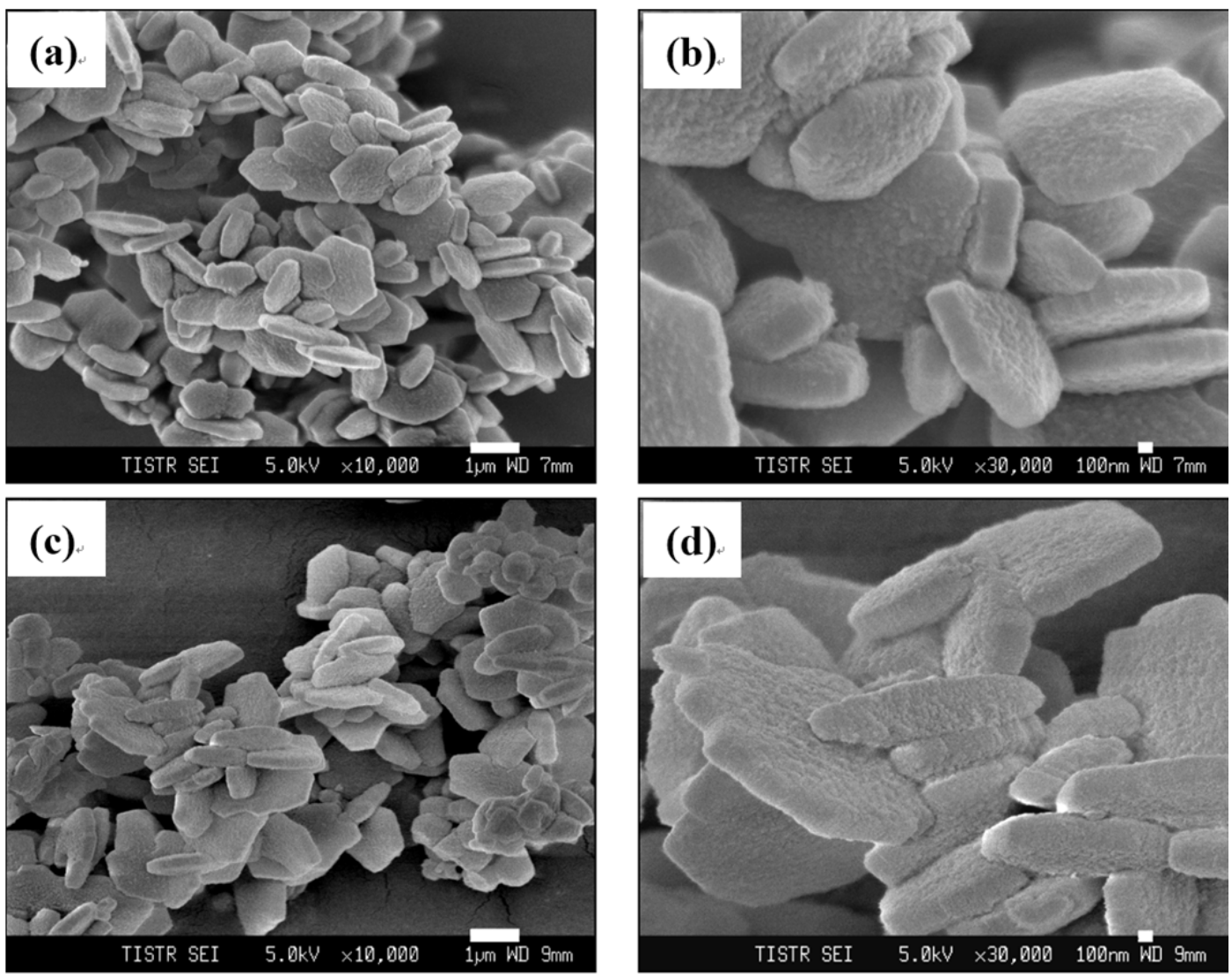

Fig. 2. HRSEM photos of the unconventional 15SA-SBA-15-p catalyst: (a and b) fresh and (c and d) after the second regeneration. 

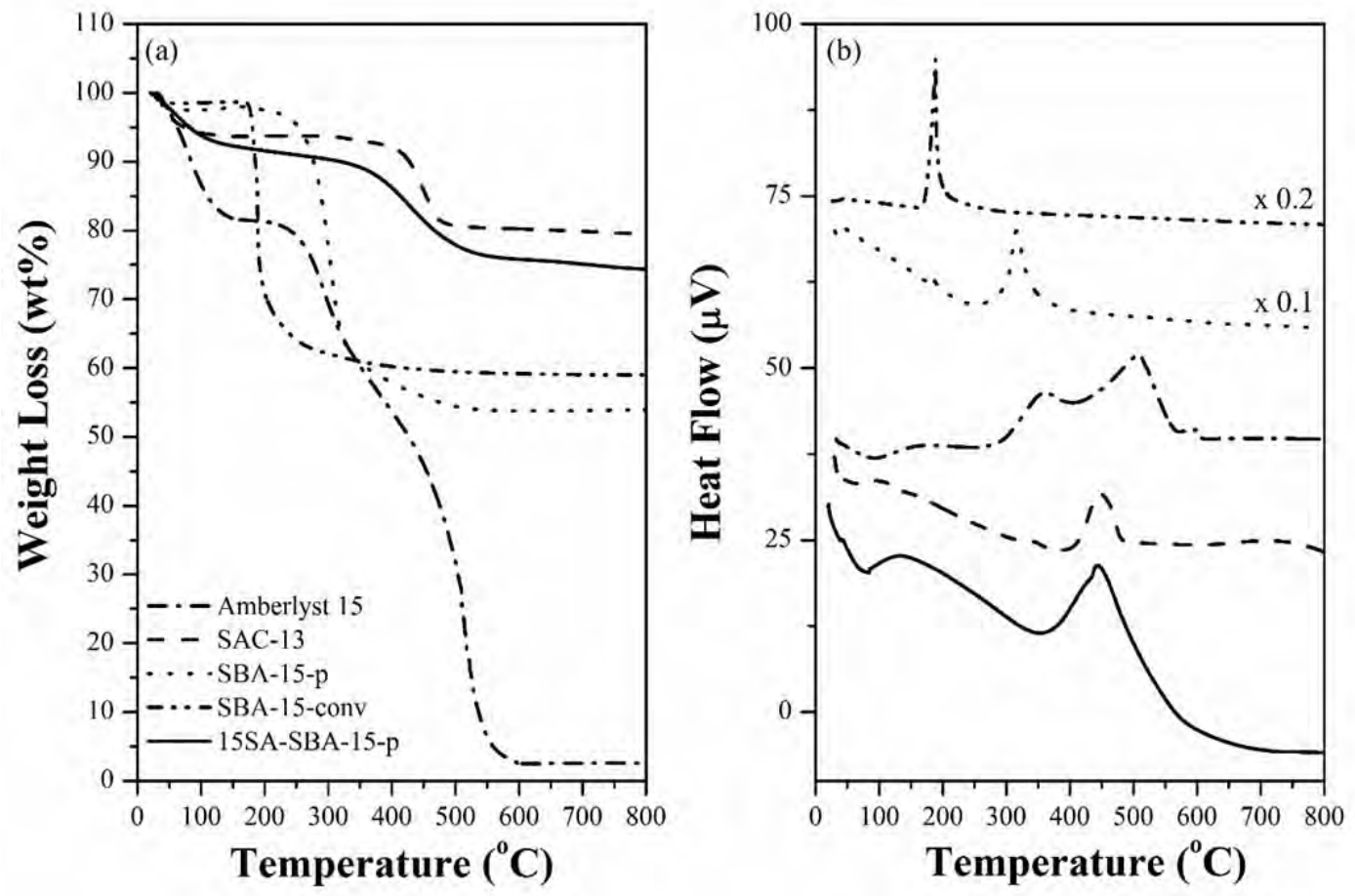

Fig. 3. (a) TGA and (b) DTA profiles of the unconventional 15SA-SBA-15-p and reference catalysts. 


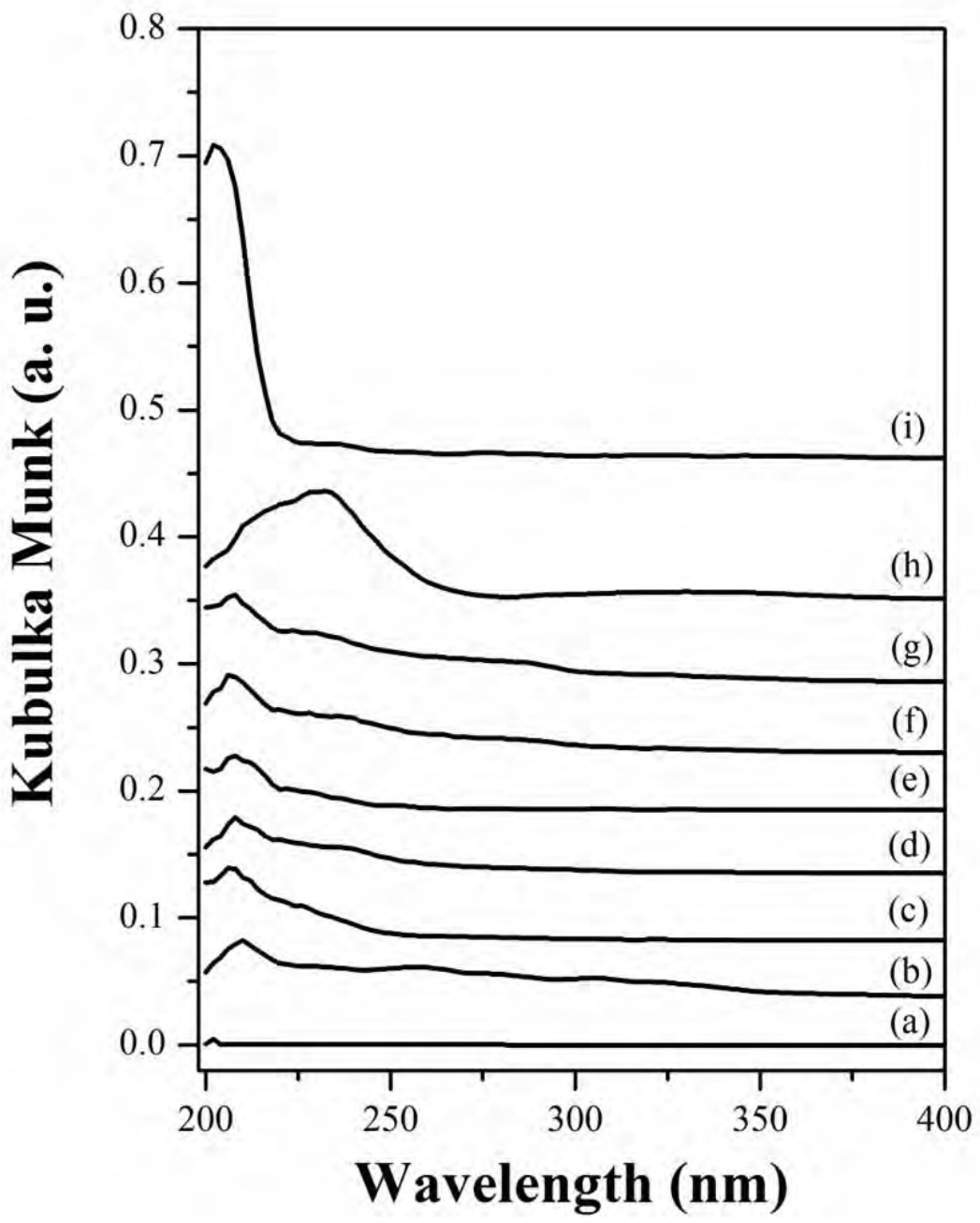

Fig. 4. DR UV-Vis spectra of (a) SBA-15-conv, (b) SBA-15-p, (c) 5SA-SBA-15-p, (d) 10SA-SBA-15-p, (e) 15SA-SBA-15-p, (f) 20SA-SBA-15-p, (g) 25SA-SBA-15-p, (h) tetragonal $\mathrm{ZrO}_{2}$ and (i) $\mathrm{ZrOCl}_{2} \cdot 8 \mathrm{H}_{2} \mathrm{O}$. 

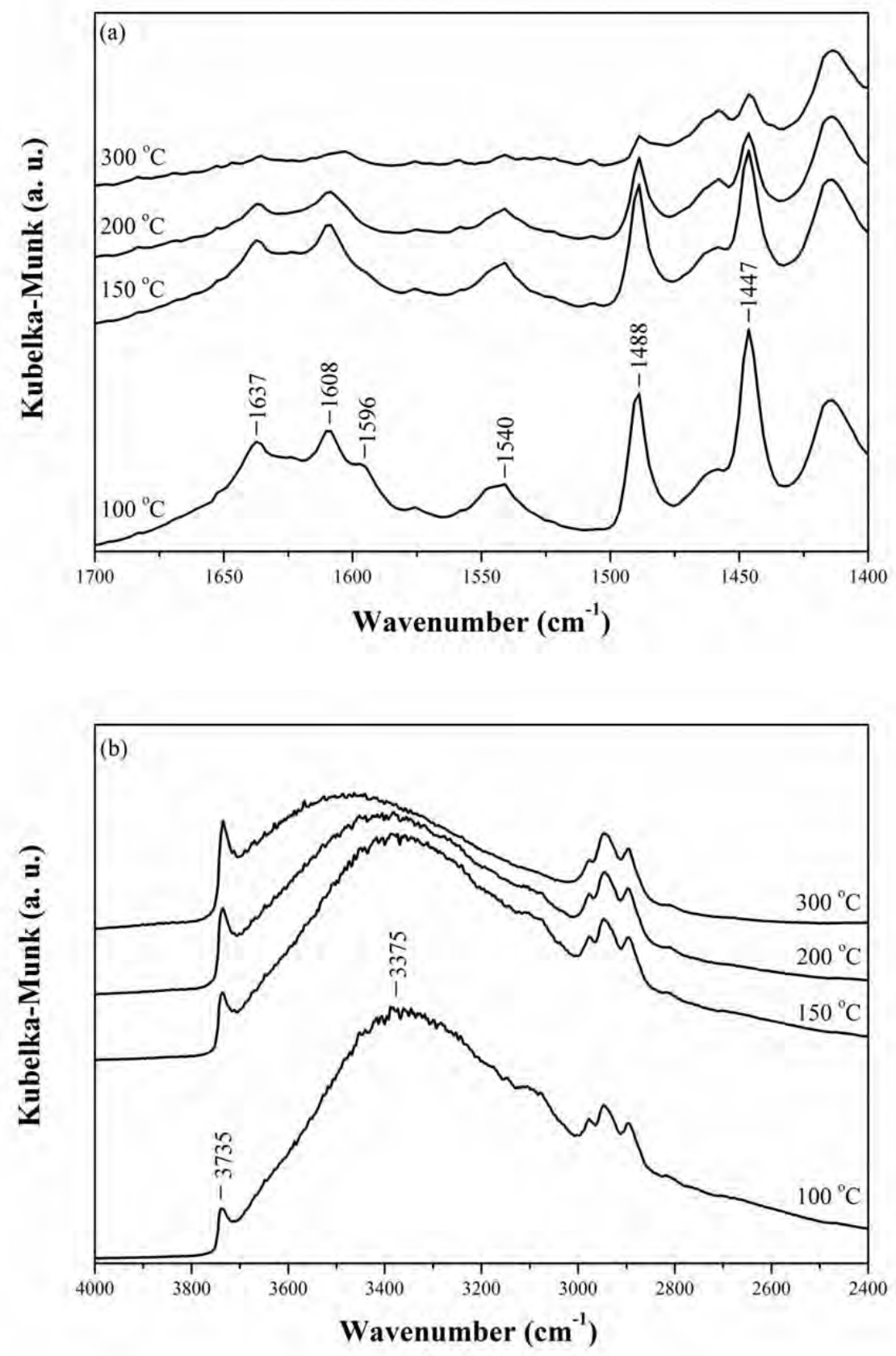

Fig. 5. DRIFT spectra of pyridine adsorbed on the unconventional 15SA-SBA-15-p catalyst recorded at $100-300{ }^{\circ} \mathrm{C}$ : (a) pyridine region and (b) hydroxyl region. 


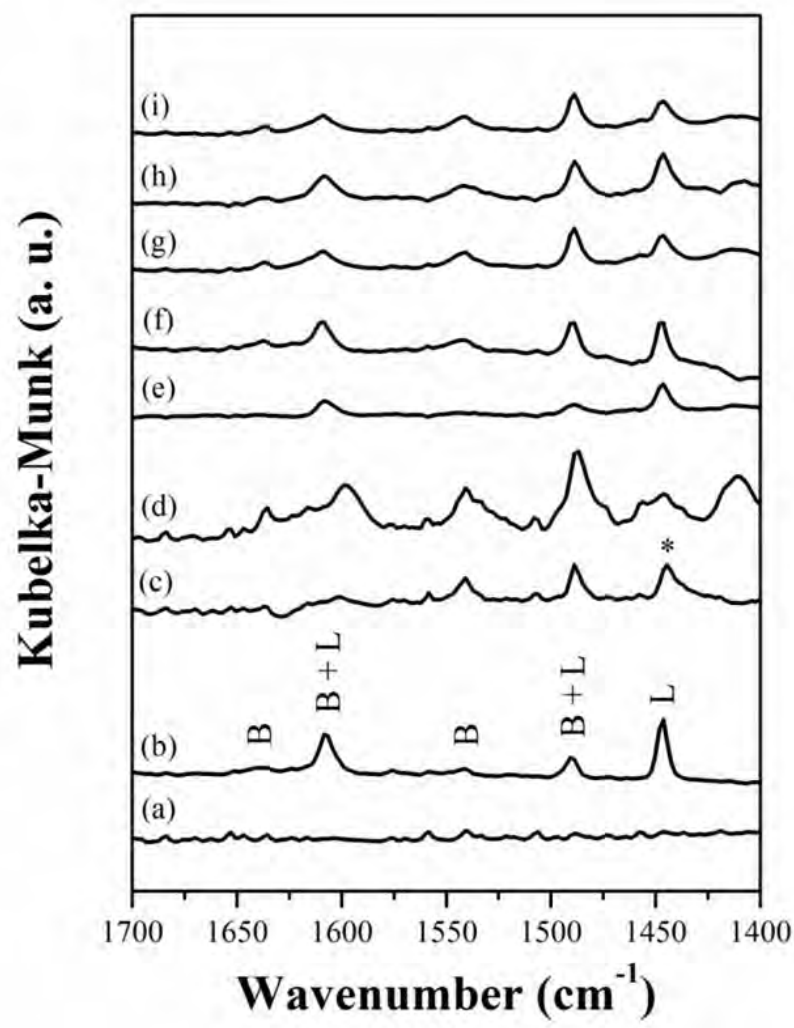

Fig. 6. DRIFT spectra of pyridine adsorbed on (a) SBA-15-conv, (b) SBA-15-p, (c) SAC-13, (d) Amberlyst-15, (e) 5SA-SBA-15-p, (f) 10SA-SBA-15-p, (g) 15SA-SBA-15-p, (h) 20SA-SBA-15-p and (i) 25SA-SBA-15-p catalysts recorded at 200 ${ }^{\circ} \mathrm{C}$. The asterisk represents the pyridine molecules adsorbed on organic carboxyl or hydroxyl groups. 

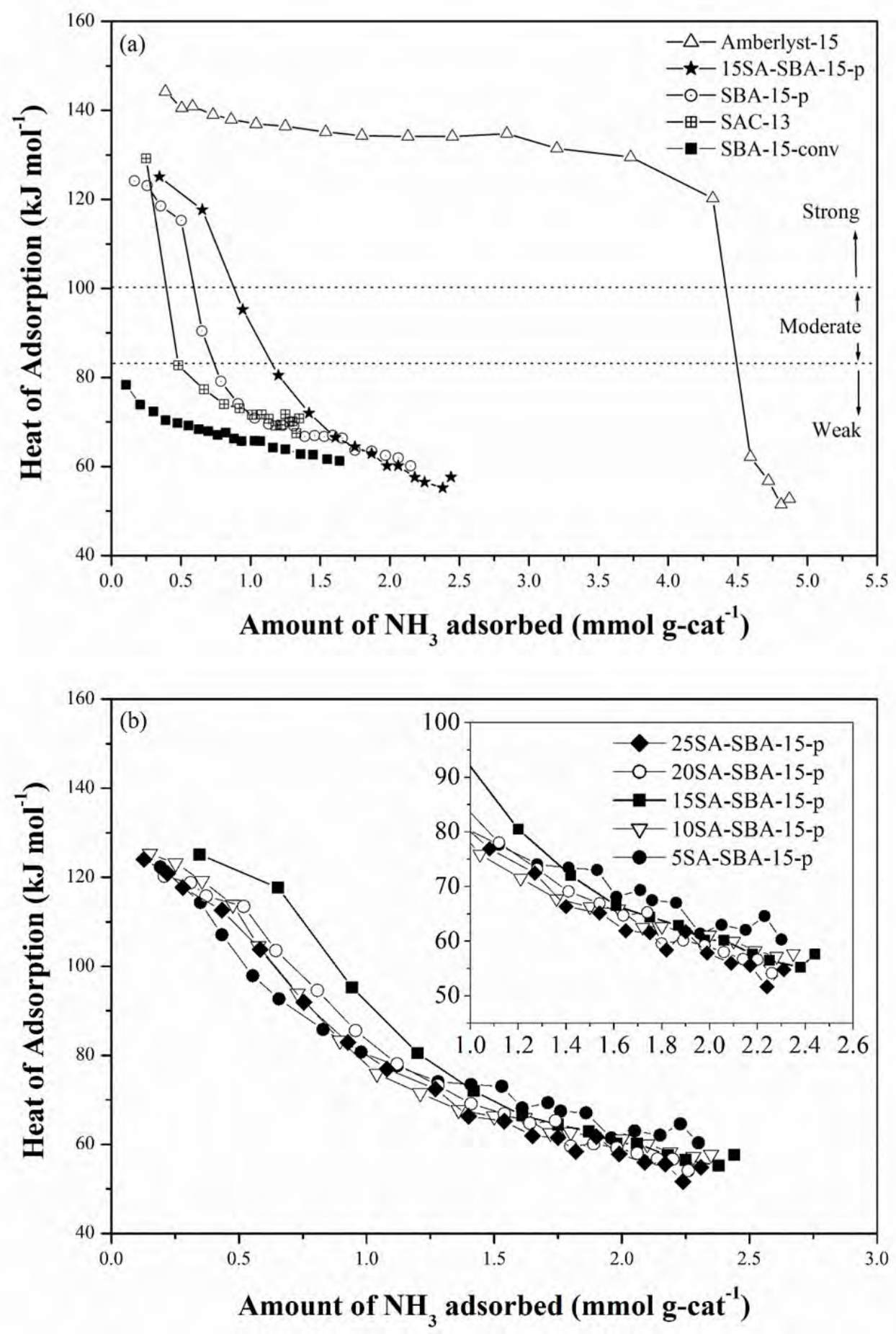

Fig. 7. Differential heat of $\mathrm{NH}_{3}$ adsorption over the unconventional 15SA-SBA-15-p and reference catalysts. 


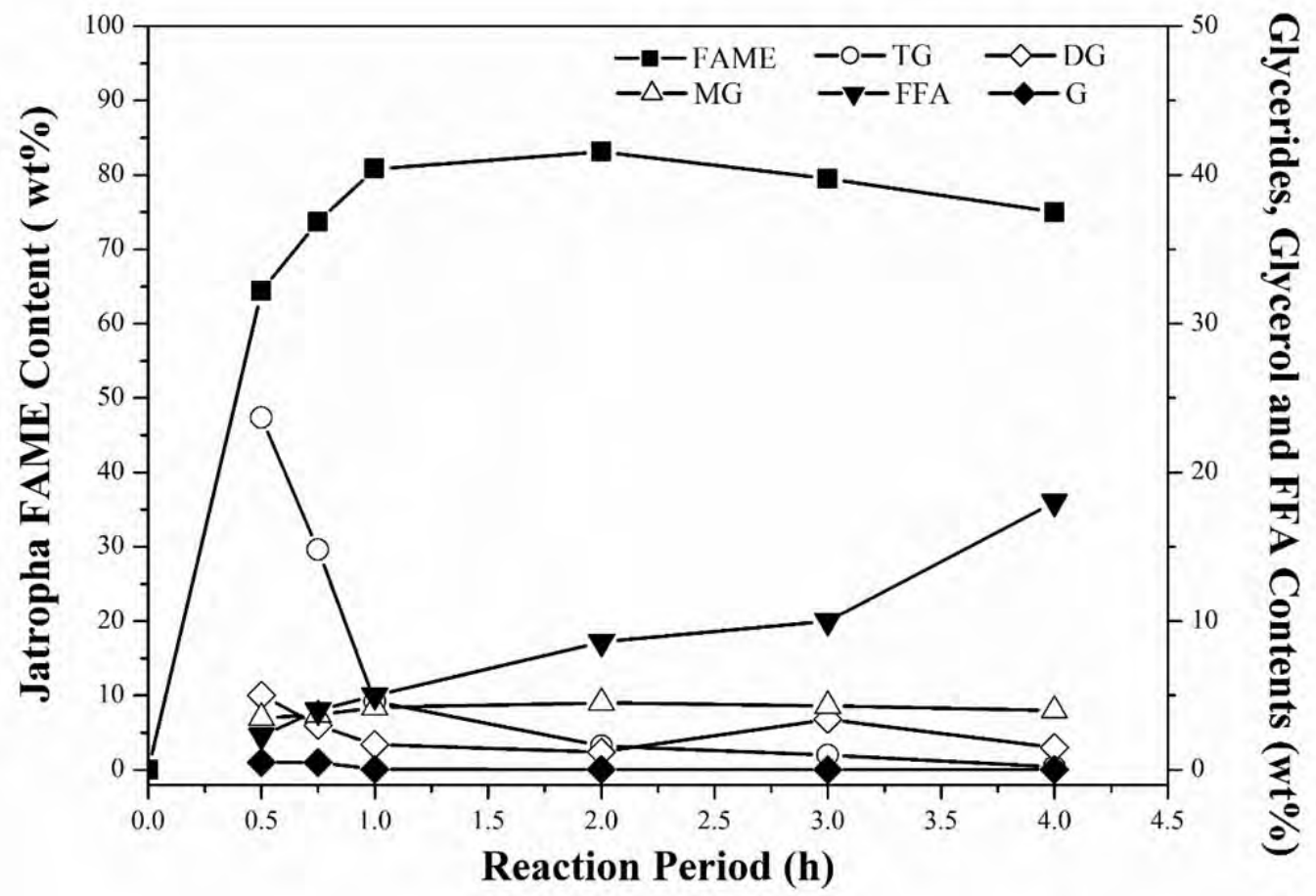

Fig. 8. Transesterification of CJO with methanol as a function of reaction period over the unconventional 15SA-SBA-15-p catalyst at $200{ }^{\circ} \mathrm{C}$ and autogeneous pressure. 

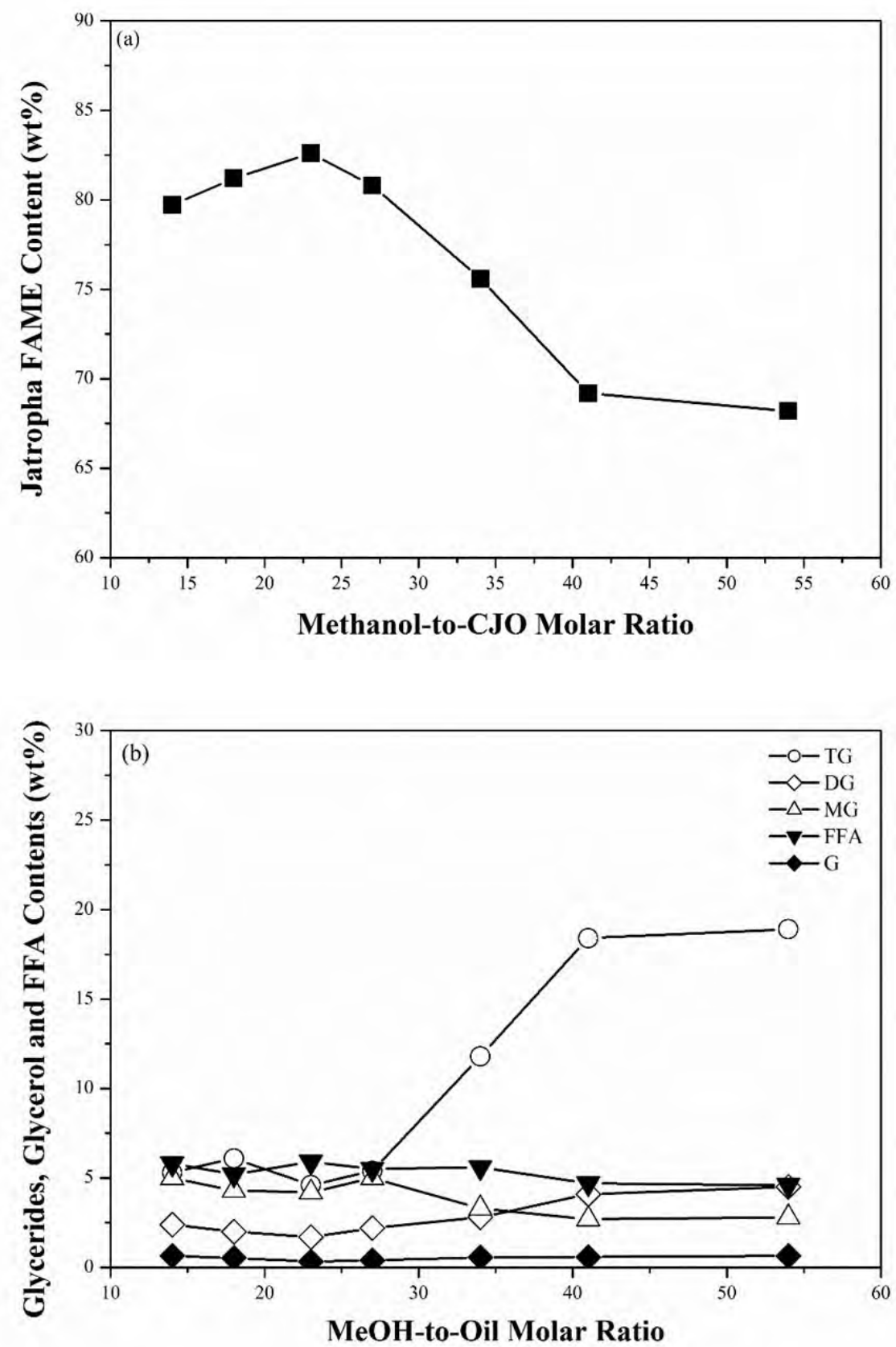

Fig. 9. Effect of methanol-to-CJO molar ratio on (a) the Jatropha FAME content and (b) the distribution of unwanted byproducts over the unconventional 15SA-SBA-15-p catalyst at $200{ }^{\circ} \mathrm{C}$ for $1 \mathrm{~h}$. 

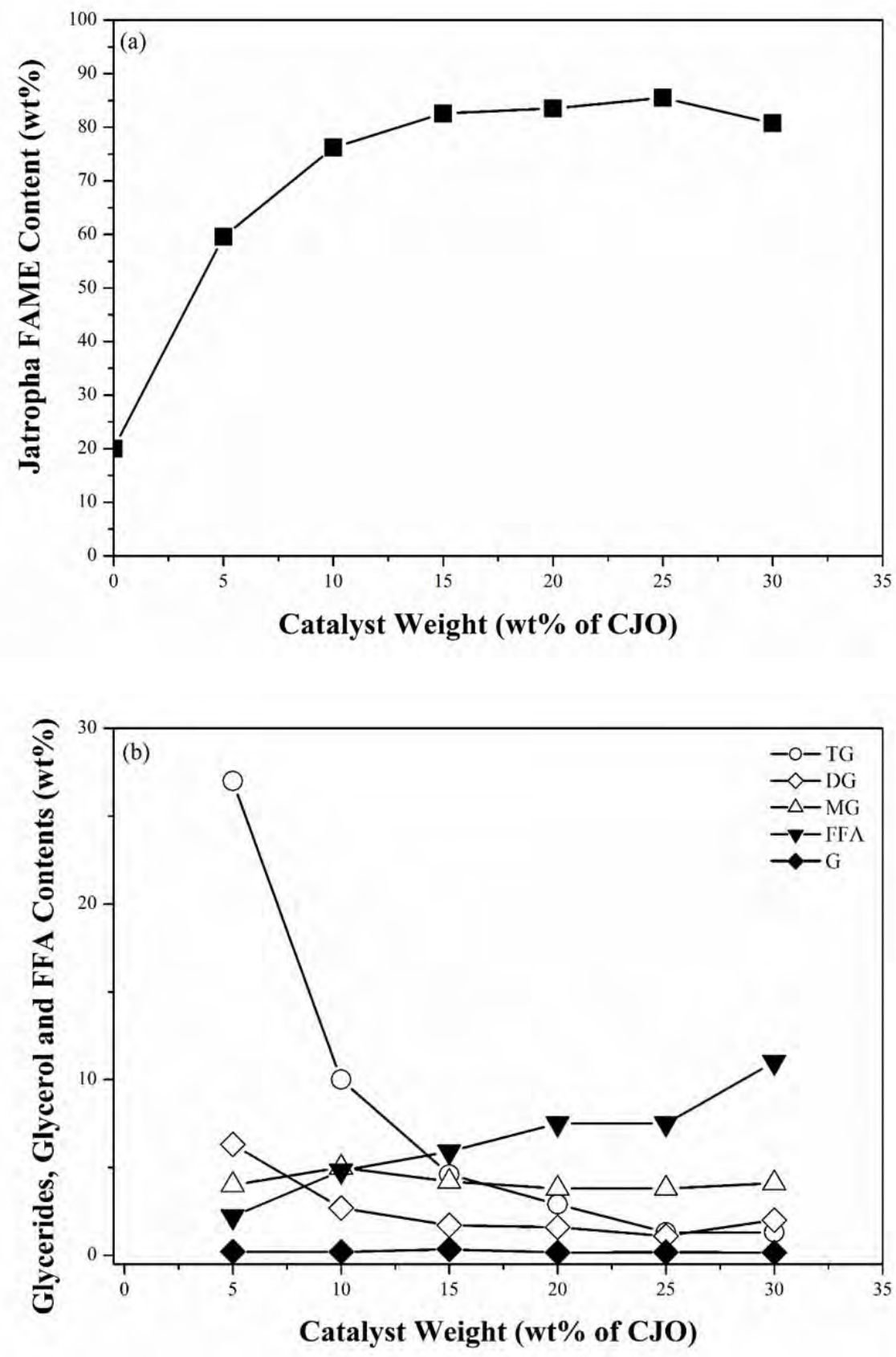

Fig. 10. Effect of catalyst weight on (a) the Jatropha FAME content and (b) the distribution of unwanted byproducts over the unconventional 15SA-SBA-15-p catalyst at $200{ }^{\circ} \mathrm{C}$ for $1 \mathrm{~h}$. 


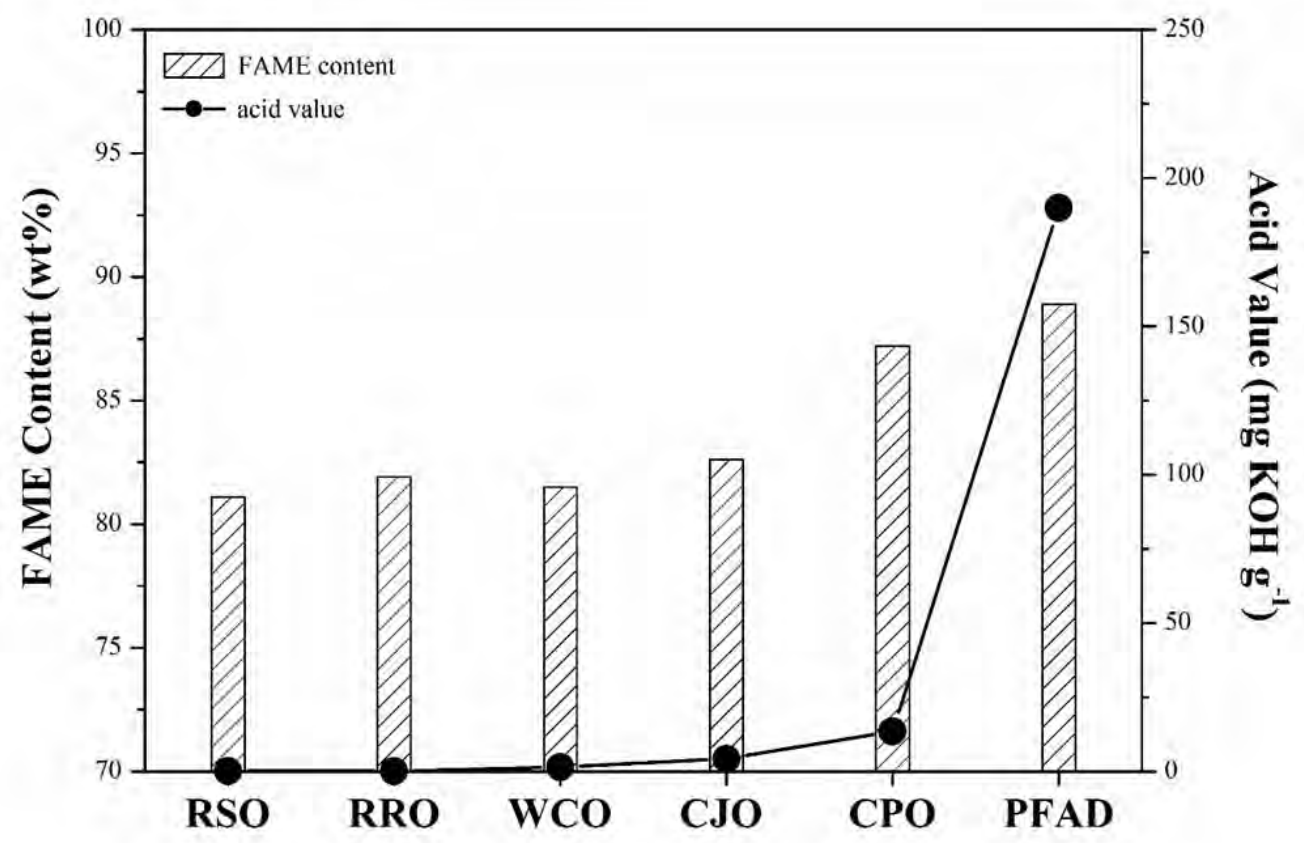

Fig. 11. Synthesis of BDFs derived from various vegetable oils over the unconventional 15SA-SBA-15-p catalyst at $200{ }^{\circ} \mathrm{C}$ and autogeneous pressure. 
Graphical Abstract to Applied Catalyst A: General

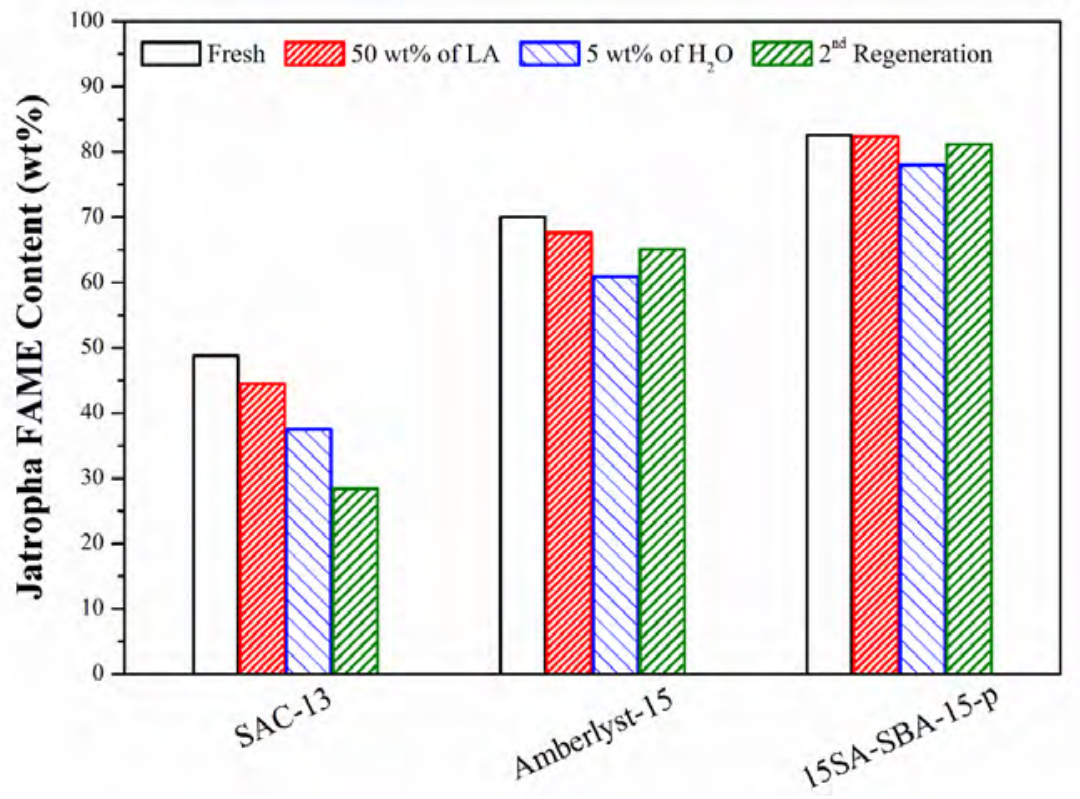

